\title{
ESTADO DO RIO DE JANEIRO: DAS CAPITANIAS HEREDITÁRIAS À UMA NOVA DIVISÃO REGIONAL ${ }^{1}$
}

\author{
RIO DE JANEIRO STATE: FROM HEREDITARY CAPITANES TO A NEW REGIONAL DIVISION
}

\author{
Miguel Angelo Ribeiro ${ }^{1}$ \\ ${ }^{1}$ Universidade do Estado do Rio de Janeiro (UERJ), Rio de Janeiro, RJ, Brasil
}

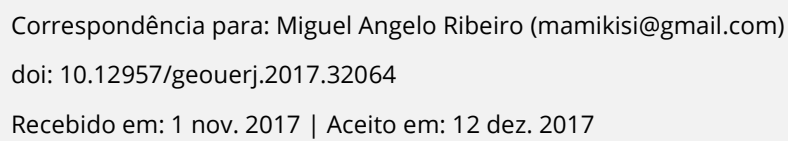

\section{RESUMO}

Analisar e discorrer sobre o território fluminense é o cerne deste artigo, no qual apropria-se de referências bibliográficas e dados estatísticos que ratificam as transformações desencadeadas a partir de 1975 (quando da fusão do antigo estado do Rio de Janeiro e o estado da Guanabara) aos dias atuais. Neste contexto, apresenta-se estruturado em três partes, a primeira aborda de modo resumido, algumas características que identificam o referido Estado, em relação ao contexto nacional e os contrastes entre a metrópole (município do Rio de Janeiro) e o interior. A segunda parte discorre sobre as transformações implementadas a partir de 1975 aos dias atuais, com as recentes transformações e seus rebatimentos na Nova Divisão regional em regiões geográficas, que será discutida na terceira parte. Para finalizar, apresentamos alguns problemas porque vem passando o referido território.

Palavras-chave: Estado do Rio de Janeiro; Metrópole-Interior; Transformações socioeconômicas; Regiões Geográficas; Capitanias Hereditárias.

\begin{abstract}
Analyzing and discoursing about Rio de Janeiro's territory is at the heart of this article in which it makes use of bibliographical references and statistical data that confirm the transformations unleashed from 1975 (when the former state of Rio de Janeiro and the state of Guanabara were marged) to the present day. In this context, it is structured in three parts, the first one addresses in a summarized way, some characteristics that identify the State described, in relation to the national context and the contrasts between the metropolis (Municipality of Rio de Janeiro) and the countryside. The second part discusses the transformations implemented from 1975 to the present day, with the recent transformations and their refutations in the New Regional Division in geographical regions which will be discussed in the third part To conclude, we present some problems that the territory presented has been passing through.
\end{abstract}

Keywords: State of Rio de Janeiro; Metropolis-Coutryside; Socioeconomic transformations; Geographical Regions; Hereditary Captaincies.

\section{CONSIDERAÇÕES INICIAIS}

\footnotetext{
${ }^{1}$ Este artigo foi elaborado para o evento IV Seminário do Rio de Janeiro, ocorrido na UERJ em agosto de 2017. Em decorrência da complexidade dos temas tratados, há lacunas no referido artigo. Para tanto, foram selecionados assuntos os mais importantes e oportunos para dar conta das transformações do território fluminense. São pontos de vista do autor. Trata-se da busca do sentido geográfico dos fatos ou fenômenos ocorridos nas dimensões espacial e temporal, os quais são de minha inteira responsabilidade. Não poderia deixar de agradecer ao professor Glaucio Marafon pelo convite para participar do referido evento; a presteza da geógrafa Monica O'Neill, da Coordenação de Geografia do IBGE, pela elaboração de mapas; ao pesquisador e orientando de doutorado Paulo Wagner Marques, pelo resumo da metodologia da nova divisão regional; ao mestre em Geografia Nathan Nunes, pela ajuda incondicional nas trocas de ideias e elaboração do texto, como também da construção do anexo 2; à João Carlos Rodrigues, pela elaboração do abstract; à pesquisadora do IBGE Ana Maria Fernandes da Costa e a Geógrafa Tereza Coni Aguiar, pela extrema atenção na correção das imperfeições de redação. Sem tais contribuições este artigo não teria sido concretizado.
} 
Para Glaucio Marafon, pesquisador e incentivador dos estudos do território fluminense, com apreço acadêmico.

Para abordar e analisar do ponto de vista acadêmico o Estado do Rio de Janeiro, não poderia deixar de trazer um pouco de minha trajetória a partir de 1998.

Analisar, interpretar e discutir o referido território, como recorte espacial, vincula-se à minha inserção na UERJ (Universidade do Estado do Rio de Janeiro), a partir do referido ano, como professor visitante do antigo Departamento de Geografia, hoje Instituto de Geografia (IGEOG), elaborando como pesquisador o Atlas do Estado do Rio de Janeiro (RIBEIRO; O'NEILL, 2000). Neste ano concluí meu doutorado no Instituto de Geociências, do Departamento de Geografia da UFRJ e aposentei-me do IBGE, após 28 anos como pesquisador no Departamento de Geografia, atualmente Coordenação de Geografia.

Ingressei no Departamento de Geografia da UERJ em 2000, após concurso público, sendo convidado para participar como colaborador do NEGEF (Núcleo de Estudos de Geografia Fluminense) pelos professores Glaucio Marafon e João Rua, que coordenavam à época o referido núcleo de pesquisa. Neste núcleo me inseri em várias atividades como consultor de atlas municipais fluminenses, entre outras atividades, mas a grande contribuição, juntamente com o professor Glaucio Marafon, é a organização da obra Revisitando o Território Fluminense, que encontra-se em seu sexto volume (2003, 2008, 2010, 2012, 2015). Esta obra envolve artigos de discentes de graduação, mestrado e doutorado e, atualmente, também de profissionais, principalmente da Geografia e de Ciência afins (MARAFON; RIBEIRO, no prelo).

Trata-se de uma das poucas obras que contemplam a dimensão espacial fluminense, e a qual tenho orgulho de participar como organizador, junto com o professor Marafon, e os artigos que a compõe nestes seis volumes serão amplamente utilizados como subsídio para as ideias que serão apresentadas neste artigo. 
Minhas pesquisas, tendo o território fluminense como recorte espacial, estão atreladas a temáticas que contemplam, principalmente as redes de localidades centrais (RIBEIRO, 2004; 2016), segunda residência (domicílios de uso ocasional) (RIBEIRO; COELHO, 2008), relações cidade/campo, urbano e rural (RIBEIRO, 2002, RIBEIRO; O'NEILL, 2012), turismo, com vários artigos publicados em livros e periódicos.

Além da atividade de pesquisa, atuo como docente, lecionando na graduação, desde o ano 2000, a disciplina Geografia do Estado do Rio de Janeiro; participo ainda, no Programa de Pós-Graduação em Geografia, com a disciplina Geografia e Turismo, desde sua implantação em 2003.

Minha contribuição no IGEOG, está vinculada às orientações em nível de graduação, mestrado e doutorado, nas quais, diferentes temáticas contemplam o território fluminense. Nesse sentido, participar deste IV Seminário Rio de Janeiro, de grande importância para tratar de questões pertinentes ao estado do Rio de Janeiro, me conduziu a pensar em uma abordagem geográfica que teve como fio condutor as transformações e novas dinâmicas espaciais no referido recorte estadual. Partindo de forma breve, de sua gênese, as Capitanias Hereditárias, criadas em 1534 (MOTA; LOPEZ, 2016), às quais originaram o atual Estado do Rio de Janeiro no século XIX (1815/1821), época criação da Província Fluminense (RIBEIRO, 2002), aos dias atuais (final da segunda década do século 21), uma nova Divisão Regional do Brasil em Regiões Geográficas é elaborada pela Coordenação de Geografia do IBGE (2017). Como já mencionado, as ideias expostas neste artigo estão concentradas em alguns fragmentos atrelados às transformações ocorridas no território fluminense nos últimos 40 anos, transformações estas, advindas do incremento populacional, do processo de urbanização, de uma nova divisão territorial do trabalho e de uma nova divisão regional.

Desse modo, analisar e discorrer sobre o referido território é o cerne deste trabalho, no qual apropriase de referências bibliográficas e dados estatísticos que ratificam as transformações desencadeadas a partir de 1975 (quando da fusão do antigo estado do Rio de Janeiro e o estado da Guanabara) aos dias atuais. 
O artigo apresenta-se estruturado em três partes. A primeira aborda de modo resumido, algumas características que identificam o referido Estado, em relação ao contexto nacional e os contrastes entre a metrópole (município do Rio de Janeiro) e o interior, conforme apontou Ribeiro (2002). A segunda parte discorre sobre as transformações implementadas a partir de 1975 aos dias atuais, com as recentes transformações e seus rebatimentos na Nova Divisão regional em regiões geográficas, que será abordada na terceira parte.

Para finalizar, apresentamos alguns problemas porque vem passando o Estado do Rio de Janeiro e um novo questionamento é elaborado.

\section{Reflexões sobre o espaço fluminense: a metrópole e o interior}

O território fluminense, a partir de 1975, apresenta uma nova configuração de ordem políticoadministrativa (mapa 1), em decorrência da fusão dos antigos estados do Rio de Janeiro e da Guanabara (LESSA, 2000, RIBEIRO, 2002), retornando aos seus limites territoriais de quando a província fluminense foi criada, a partir de três Capitanias Hereditárias (MEC, 1973): São Vicente, ao sul, São Tomé, ao norte, e a Capitania Real, correspondente à porção pertencente à cidade do Rio de Janeiro, em direção ao sul do atual estado, conforme representação no mapa 2.

Unidade territorial localizada na Região Sudeste, a região concentradora de bens e serviços e de população, de acordo com Santos e Silveira (2001), é uma das menores do país, abarcando 43.900 $\mathrm{km}^{2}$, mas detendo uma das mais altas densidades populacionais, da ordem de $378,9 \mathrm{hab} / \mathrm{km}^{2}$, segundo dados estatísticos da estimativa populacional para 2016 (IBGE), além de configurar um quadro físico muito diversificado e condicionante na organização socioeconômica de seu território, conforme demonstrado por Ribeiro (2002).

Como assinalado por este autor (2002), cumpre mencionar que o estado do Rio de Janeiro possui um território, com características e identidade próprias, resultante de marcas pretéritas e recentes de processos de escalas macro e locais. 


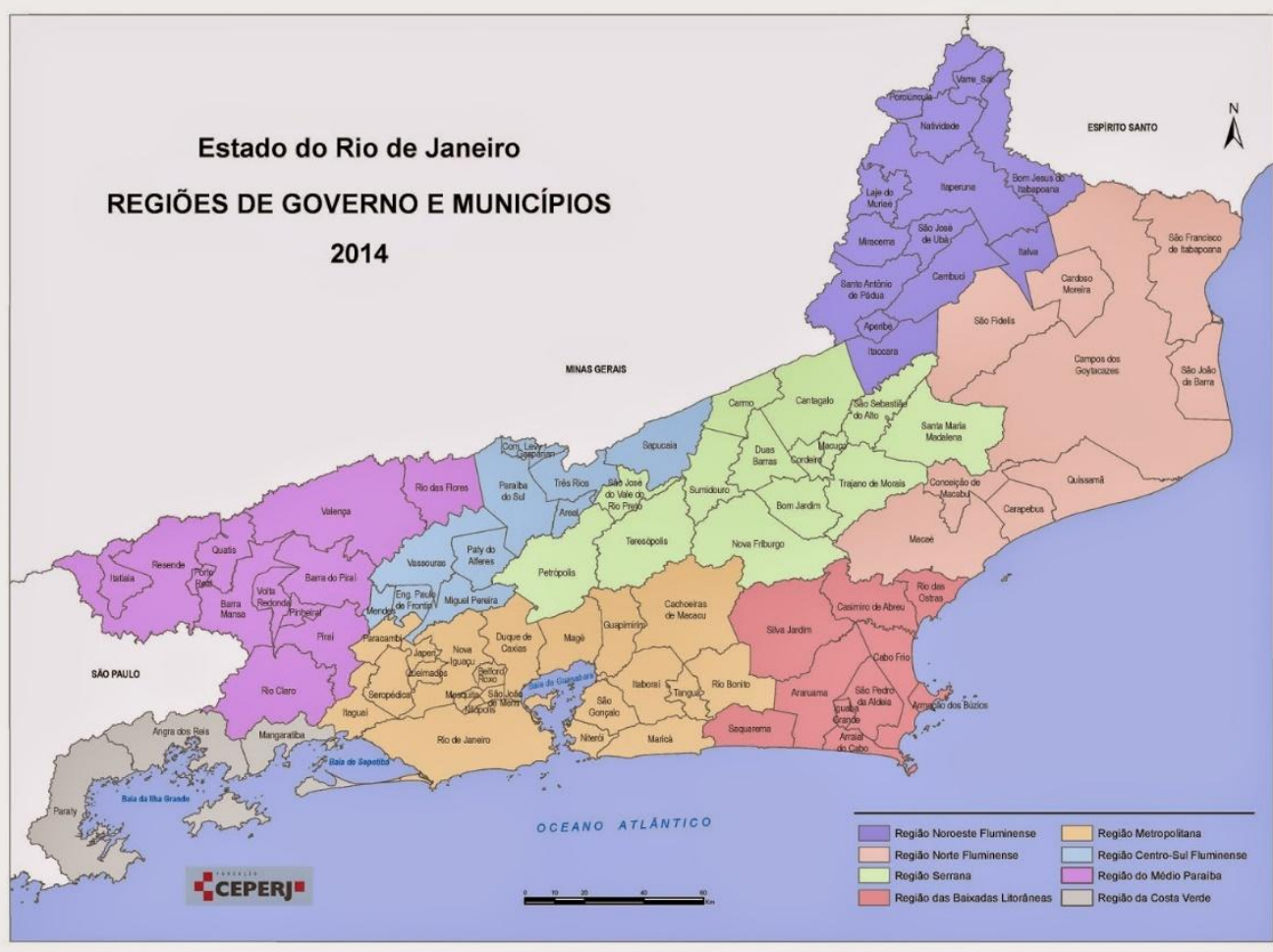

Mapa 1. Regiões de Governo, 2014. Fonte: CEPERJ, 2014

Mapa da Capitania Real

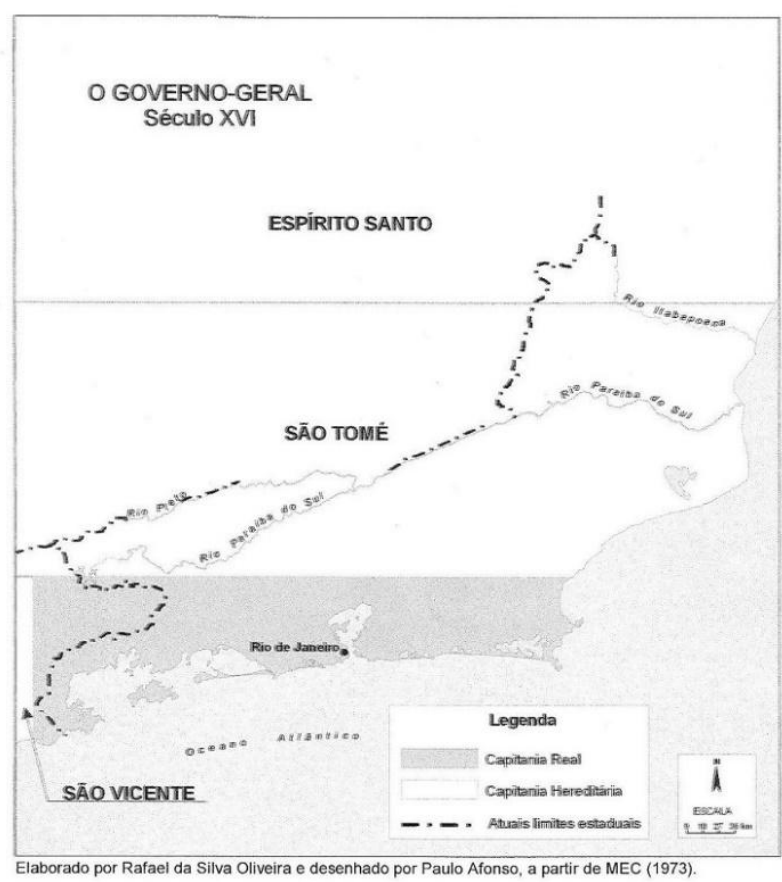

Mapa 2. Mapa da Capitania Real. 
Ribeiro (2002) identificou dois subespaços bem nítidos e contrastantes no território fluminense, a metrópole atualmente com 21 municípios, constituída pelo Rio de Janeiro como núcleo, comandando 20 municípios localizados na porção sul, na baixada litorânea e à leste da Baía de Guanabara (mapa 3), e os 71 municípios restantes, que o autor denominou de interior, ou seja, aqueles não pertencentes à metrópole e que já pertenciam territorialmente ao antigo estado do Rio de Janeiro.

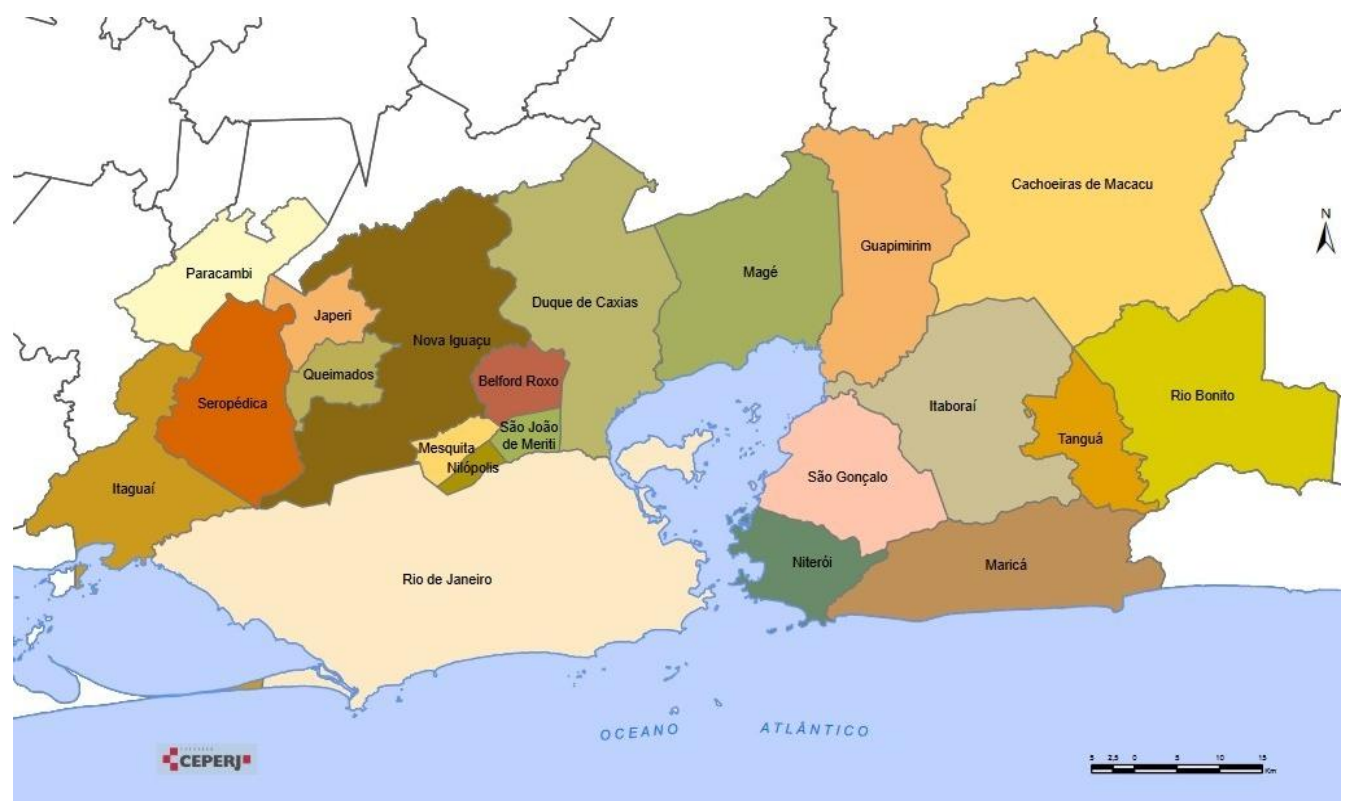

Mapa 3. Região Metropolitana do Rio de Janeiro. Fonte: CEPERJ, 2014.

Após estas considerações, o tópico seguinte apresenta transformações a partir de 1975 que contribuíram para uma nova organização espacial.

\section{Transformações socioespaciais a partir de 1975 aos dias atuais}

No território fluminense a partir de 1975, podemos destacar, grosso modo, quatro características, que ratificam nas escalas nacional e estadual o papel importante da metrópole do Rio de Janeiro.

i) A importância da capital, Rio de Janeiro, em decorrência da concentração populacional expressiva de bens e serviços, que desde 1973 configura uma Região Metropolitana, e atualmente registra 21 municípios e que concentra mais de $75,0 \%$ da população estadual, 
correspondendo a aproximadamente 12 milhões de residentes, além de um setor de serviços de diferentes naturezas (PACHECO, 1998), dentre eles firmas de tecnologia de informação. Cumpre registrar que a referida capital se relaciona ao setor de comércio e serviços, desde sua gênese e, atualmente, os serviços atrelados à tecnologia da informação, tem papel importante, com empresas articulando-se e conectando-se com a rede mundial (ARAÚJO, 2017), enquanto no interior do estado, o setor industrial se faz presente de forma pontual - Campos dos Goytacazes/Macaé; Petrópolis/Nova Friburgo/Teresópolis; Volta Redonda/Barra Manda/Resende; e Angra dos Reis (RIBEIRO; O'NEILL, 2012; 2015).

ii) Outro fato importante é a ausência de integração e identidade entre a capital e o interior, antes e após a fusão, segundo apontou Davidovich (2000). Como exemplo desta afirmativa, podemos mencionar que os nascidos na cidade do Rio de Janeiro consideram-se cariocas e não fluminenses, como aqueles nascidos no restante do estado (HOUAISS, 2009, p.1361). Outro aspecto que evidencia esta falta de pertencimento, e afirmação do Rio de Janeiro como centralidade político-administrativa e econômica, diz respeito ao campeonato de futebol estadual, no qual o primeiro turno é denominado de Taça Guanabara e o segundo de Taça Rio, quando na verdade este pleito deveria ser denominado de Campeonato do Estado do Rio de Janeiro.

iii) Há um domínio da população urbana sobre a rural. A população urbana fluminense superou a rural antes da metade do século XX, desde a década de 1940, enquanto o Brasil só apresentou esta situação em 1970. Alguns aspectos podem ser evidenciados no tocante a esta característica, visto que o referido estado apresenta a maior taxa de população urbana do país, na qual 96,6\% vivendo em cidades e vilas, segundo critério oficial apontado pelo IBGE. O que explica a população fluminense residindo prioritariamente em domicílios urbanos está relacionado ao próprio crescimento vegetativo; a migração com destino urbano; e a expansão pelas prefeituras do perímetro urbano, atrelado ao recolhimento do IPTU em nível municipal; enquanto o ITR (Imposto Territorial Rural) é recolhido pelo 
Governo federal e repassado aos municípios. Segundo estudo realizado por Ribeiro e O’Neill $(2012 ; 2015)$, as maiores cidades fluminenses estão nos limites metropolitanos, conforme pode ser observado no mapa 4, enquanto as cidades do interior são pouco representativas do ponto de vista do tamanho populacional, consideradas de pequeno porte, pois das 71 cidades do interior, 49 apresentaram população inferior a 25 mil habitantes, segundo Censo Demográfico (IBGE, 2010). Cumpre registrar que a urbanização tem sido o principal processo de organização do território fluminense, com aspectos de macrourbanização e metropolização - núcleo e periferia metropolitanas registram os maiores totais de populações vivendo em cidades e vilas, fato explicado pelo adensamento populacional em áreas já urbanizadas e incorporação de áreas rurais no tecido urbano, conforme pode ser observado na representação do mapa da expansão urbana fluminense (mapa 5).

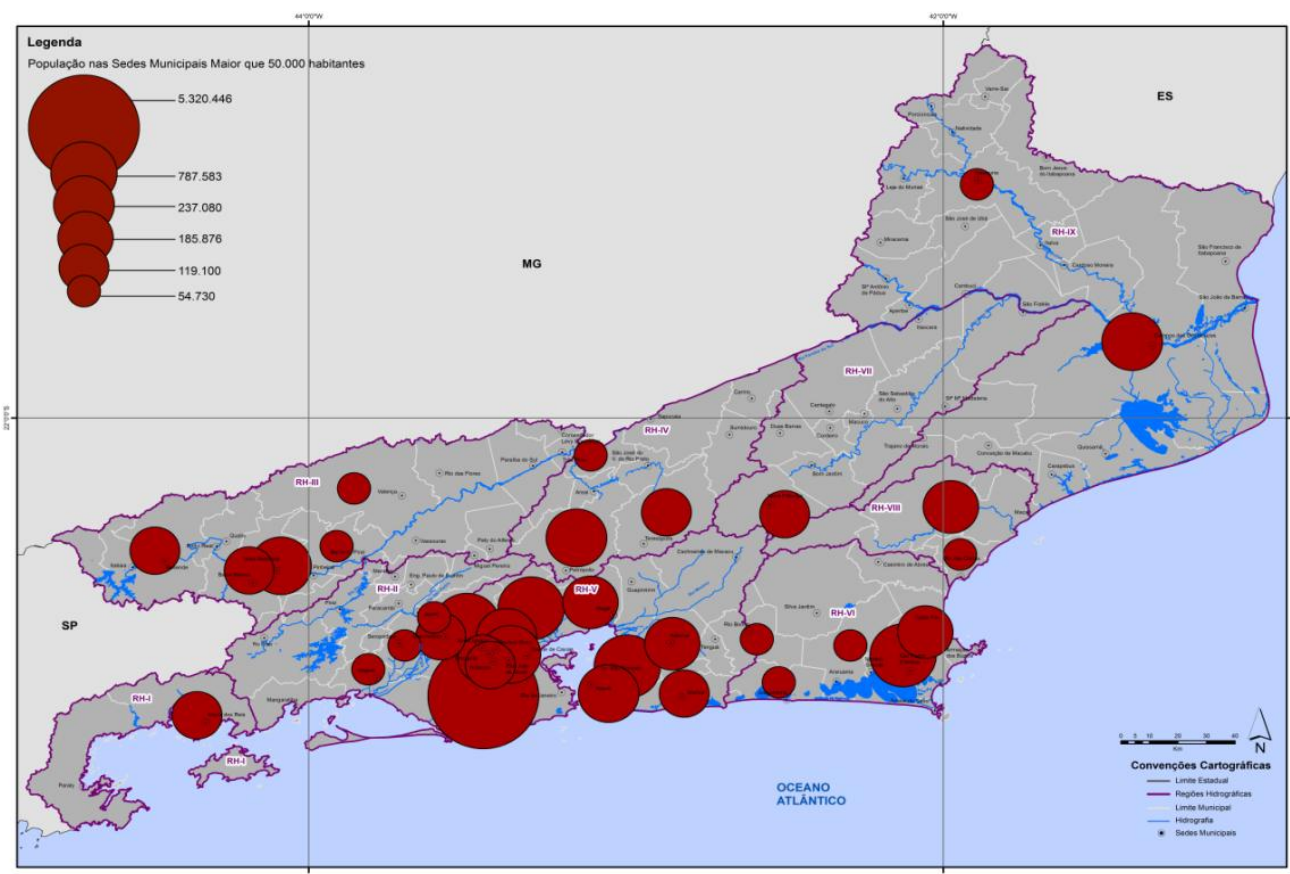

Mapa 4. Principais sedes municipais do Estado do Rio de Janeiro, 2010. Fonte: IBGE - Censo Demográfico, 2010. 


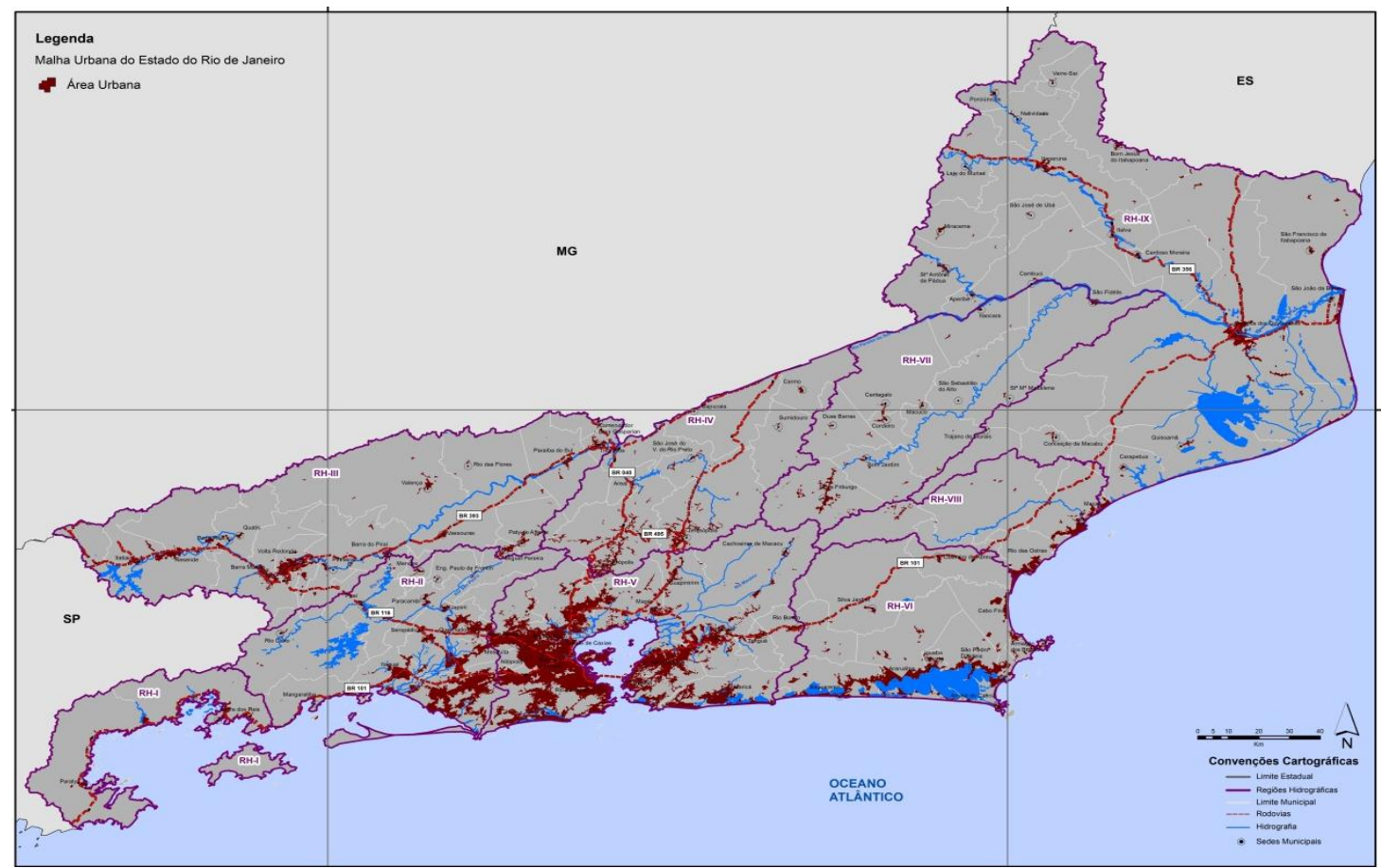

Mapa 5. Malha Urbana no Estado do Rio de Janeiro, 2010. Fonte: IBGE - Censo Demográfico, 2010.

iv) Outro fato importante está atrelado às transformações porque passou o território fluminense do final dos anos 1970 até os dias atuais, além da crise governamental porque vem passando o estado. Tais transformações são decorrentes - 1. do lazer vinculado ao turismo e à segunda residência, no qual podemos identificar das oito regiões de governo delimitadas pelo CEPERJ (2013), três regiões apresentam expressividade: as Baixadas Litorâneas, a Costa Verde e a Região Serrana, conforme estudos apontados por Ribeiro e Coelho (2008); 2. do hibridismo dos espaços rurais com a pluriatividade, onde a Região Serrana tem papel de destaque (MARAFON; RIBEIRO, 2005, MARAFON, 2012) diante das demais regiões, na qual o agricultor familiar se insere em atividades de serviços vinculadas ao turismo e à segunda residência, conforme pode ser identificado na RJ-130 (Teresópolis-Nova Friburgo). Os espaços rurais desses dois municípios mantém plantios de hortifrutíferos e desenvolvem produtos raros ou nobres (GALVÃO, 1987) que são comercializados com o município do Rio de Janeiro (SEABRA, 2008; 2015ª ; 2015b); 3. da reconversão produtiva industrial, com novos empreendimentos localizados na região do Médio Vale do Paraíba, onde a Companhia Siderúrgica Nacional, localizada no município de Volta Redonda, teve papel de destaque (MOREIRA, 2003), e que atualmente complementa 
a atividade industrial com novas indústrias, exemplificadas por montadora de caminhões e ônibus e fábrica de automóveis da Nissan em Resende e, fábrica de Hyundai em Itatiaia, todas implantadas após 2010 (OLIVEIRA, 2008, BAPTISTA, 2016). 4. da extração do petróleo, das atividades off-shore e da distribuição dos royalties, que contribuíram para um processo de emancipações municipais fluminenses, destacando-se a criação de municípios principalmente no Norte Fluminense e nas Baixadas Litorâneas, como Rio das Ostras, Armação dos Búzios, Quissamã, Carapebus, dentre outros. As obras obras de Morais (2010) e Nunes (2015) trazem contribuições relevantes sobre tais fatos. Cumpre fazer referência que com a exploração do petróleo no pré-sal, um novo "mapa" dos royalties pode ser identificado, conforme reportagem do jornal O Globo (2017), no qual Maricá desponta e já recebe mais do que Macaé, secundado por Niterói, segundo a Agência Nacional de Petróleo, Gás Natural e Biocombustíveis (gráfico 1).

BENEFICIÁRIOS DE ROYALTIES E PARTICIPAÇÕES ESPECIAIS EM 2017

(No acumulado do ano, até julho, em R\$ milhões)

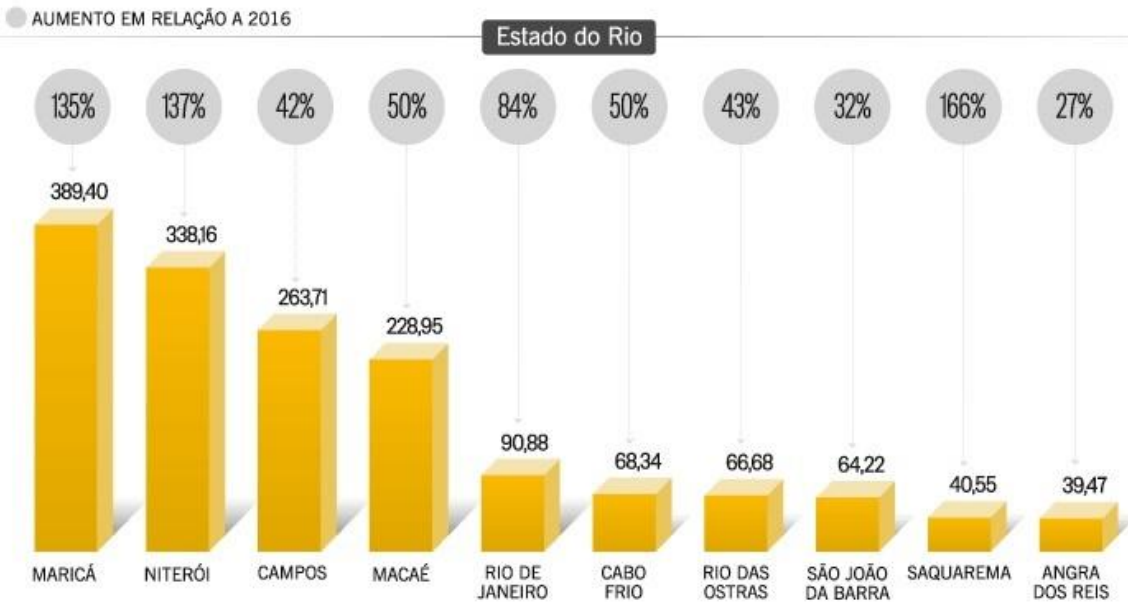

Gráfico 1. Fonte: Agência Nacional de Petróleo, Gás Natural e Biocombustíveis, 2017.

O mapa geoeconômico do estado do Rio de Janeiro sintetiza, grosso modo, a divisão territorial do trabalho na escala estadual, identificando as principais atividades econômicas desenvolvidas pelas diferentes regiões de governo e as principais centralidades. 


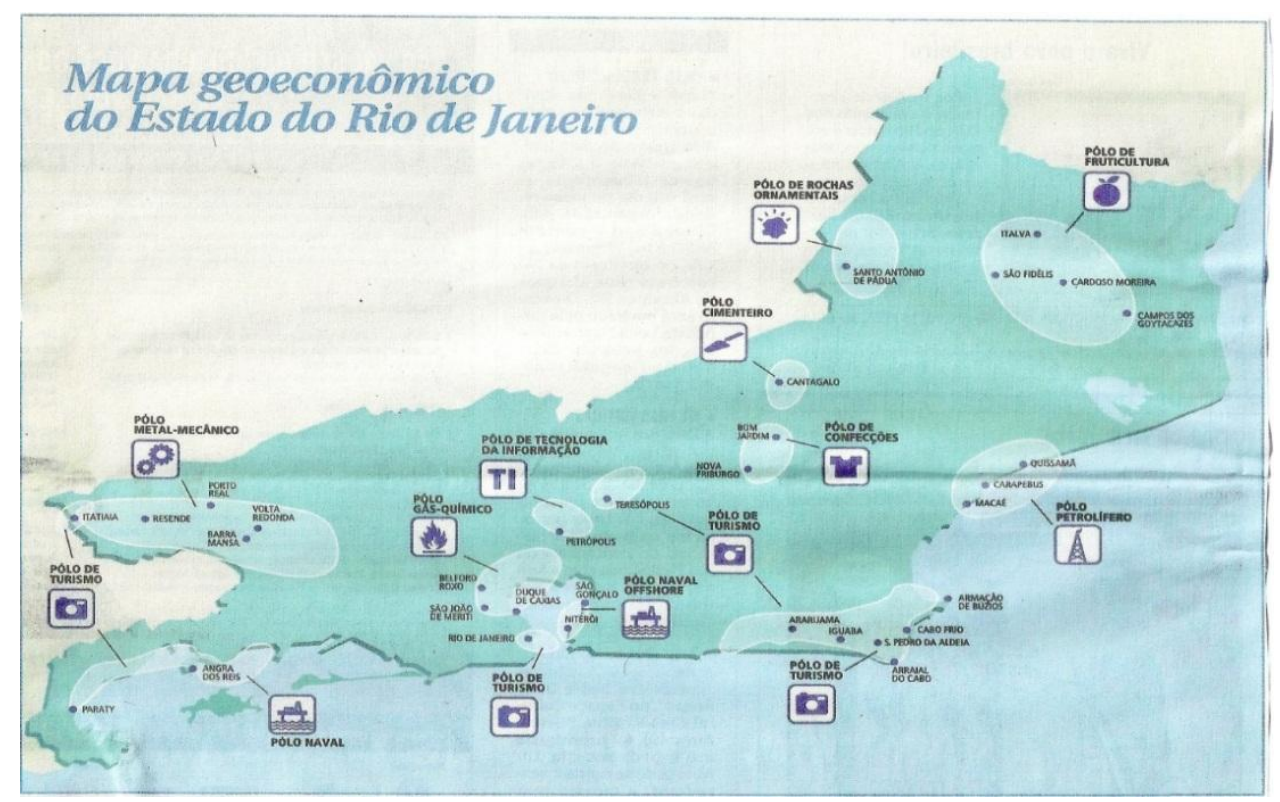

Mapa 6. Fonte: Jornal O Globo, s/d..

Mais recentemente alguns investimentos foram viabilizados no contexto estadual, dentre eles podemos citar: 1. o Arco Metropolitano, ligando o Porto de Itaguaí (antigo Porto de Sepetiba) ao COMPERJ (Complexo Petroquímico da Petrobrás), em Itaboraí, conforme discutido por Dias et al (2013); 2. o COMPERJ (figura 1), obra em fase de implantação, e na qual o referido projeto está sendo redimensionado, para o início de suas atividades (FIRJAN, 2011). Obra afetada pelos recentes escândalos ocorridos na Petrobrás e que teve como consequência sua implantação adiada; 3. o Porto do Açu, no Norte Fluminense (figuras 2 e 3), projeto que inicialmente pertencia ao grupo EBX e que hoje, é controlado pela americana EIG. Concebido para atrair metalúrgicas, o referido complexo quer transformar-se em hub de combustível natural, no qual pretende-se construir uma usina térmica e um terminal de importação de gás, com previsão de ligação com gasodutos do Sudeste (FOLHA DE SÃO PAULO, 2017, p.24). 


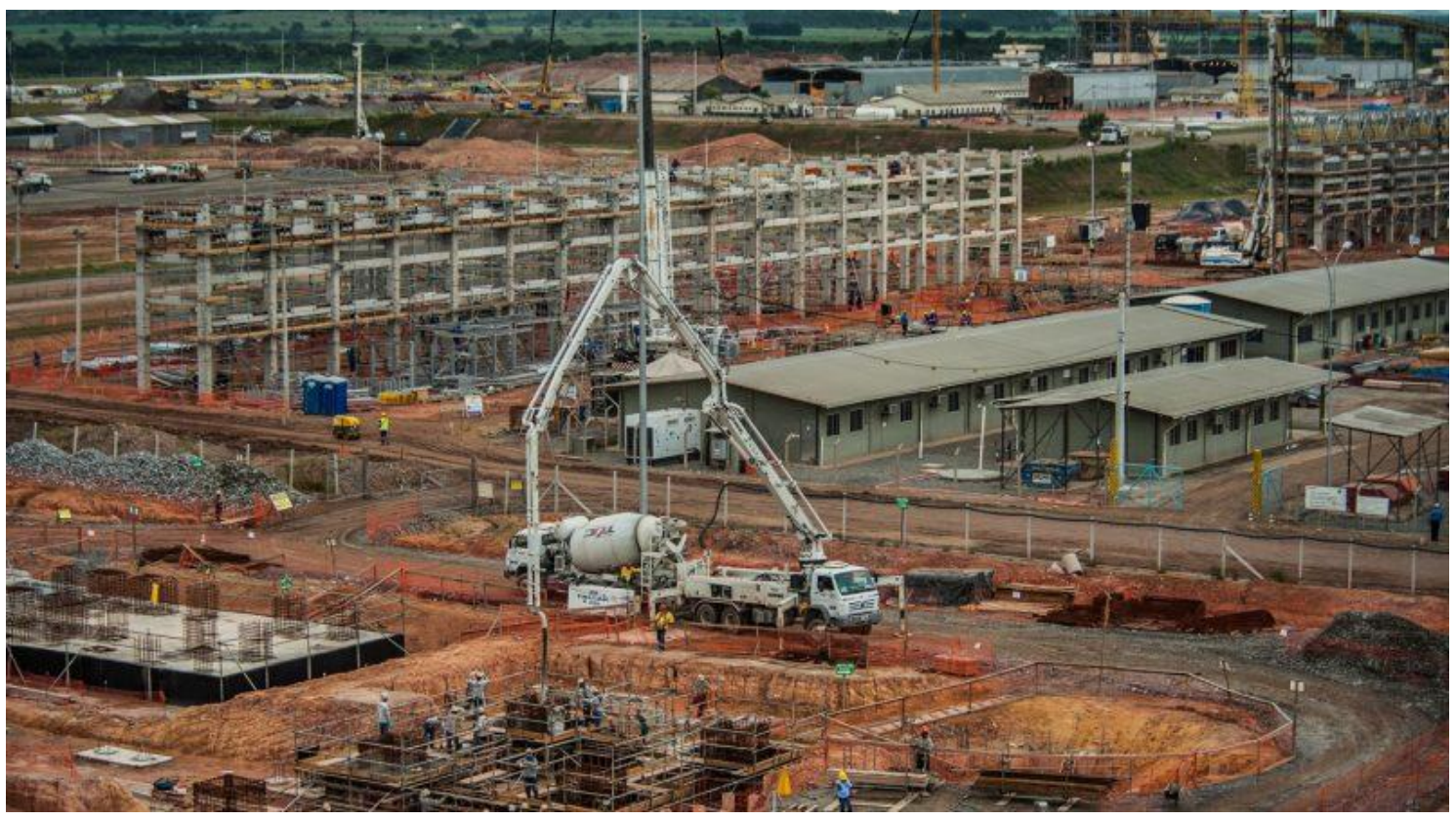

Figura 1. Obras COMPERJ - Município de Itaboraí. Fonte: http://www.atribunarj.com.br, 2017.

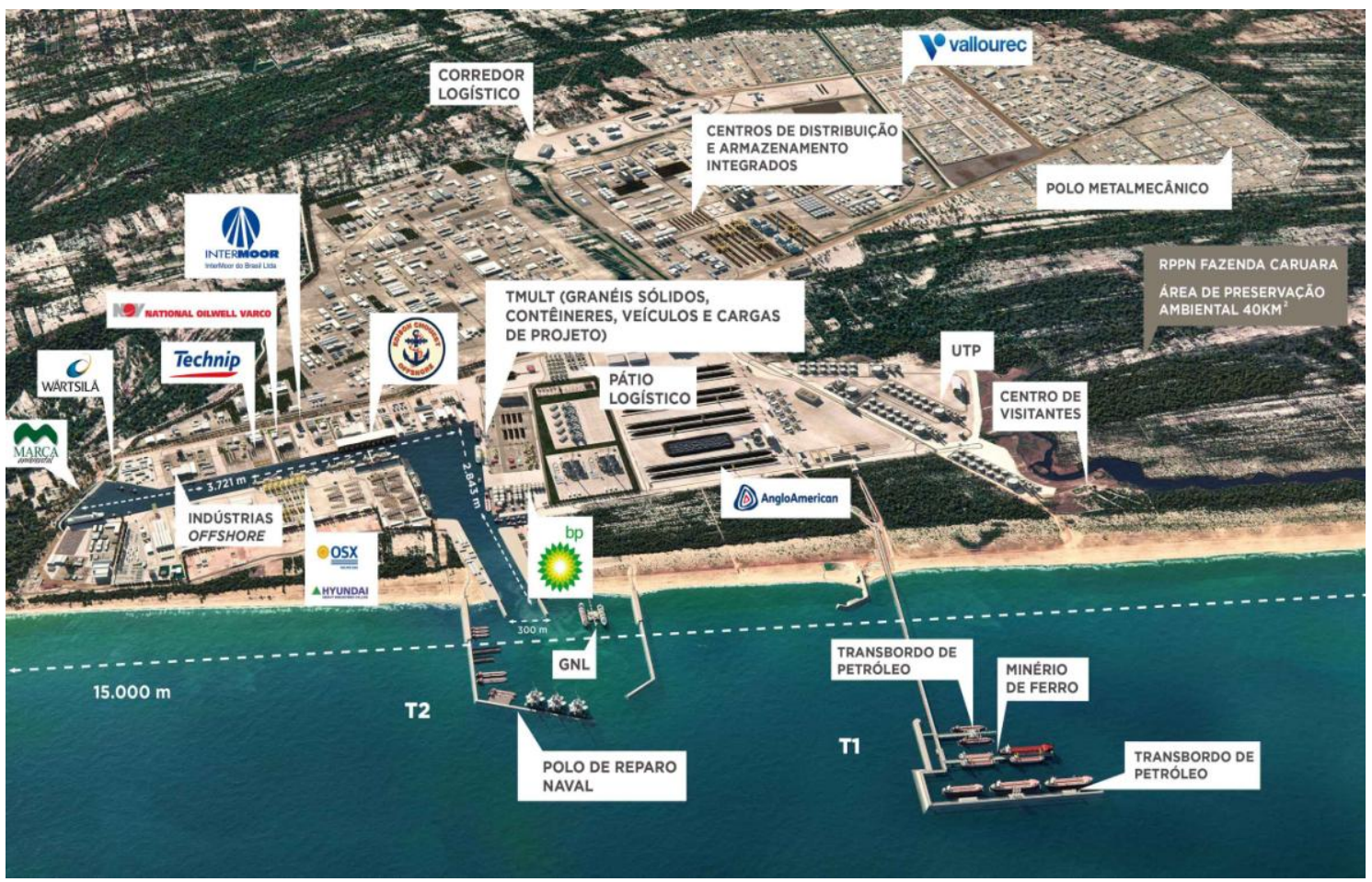

Figura 2. Projeto Porto do Açu - Município de São João da Barra. Fonte: www.prumologistica.com.br, s/d. 


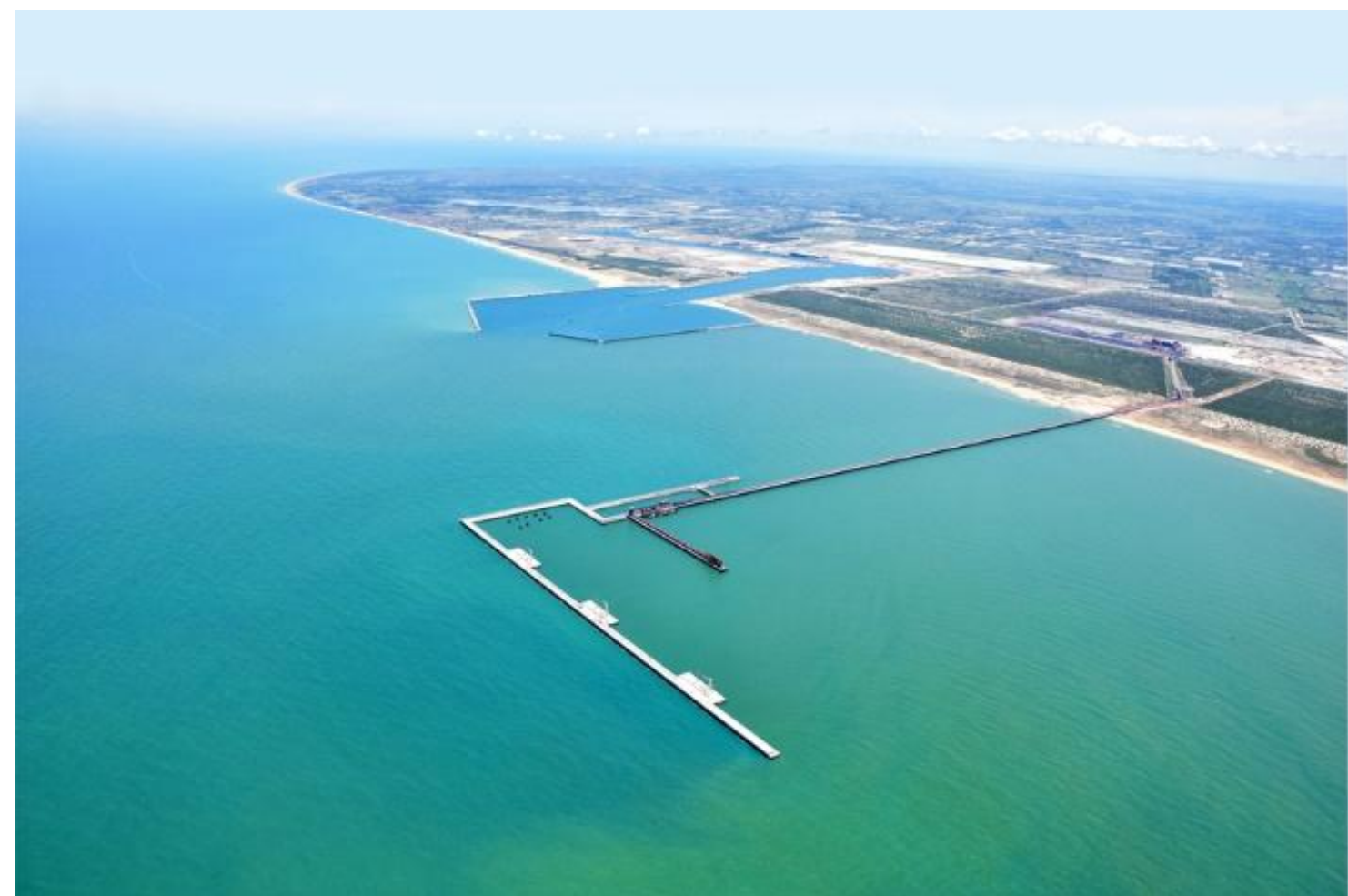

Figura 3. Fonte: www.somosassim.com.br, 2017. Projeto Porto do Açu - Município de São João da Barra.

Este empreendimento encontra-se em funcionamento desde 2014 e, conforme apontado na Folha de São Paulo, está passando por uma mudança de perfil. Cumpre destacar que o referido Porto, no primeiro semestre de 2017 foi considerado o sexto maior terminal privado do país em movimentação de cargas, segundo dados da ANTAQ; 4. e, por fim, não podemos deixar de mencionar o Complexo de Barra do Furado, como mencionado por estudos feitos pelo IPEA (2011, p.8).

É composto de um Estaleiro, no município de Quissamã; de uma Base de Apoio off-shore, e de um Centro de estocagem de combustível, ambos voltados para o mercado das atividades offshore de exploração e produção de petróleo e gás, e de um estaleiro, no município de Campos dos Goytacazes (figura 4). 


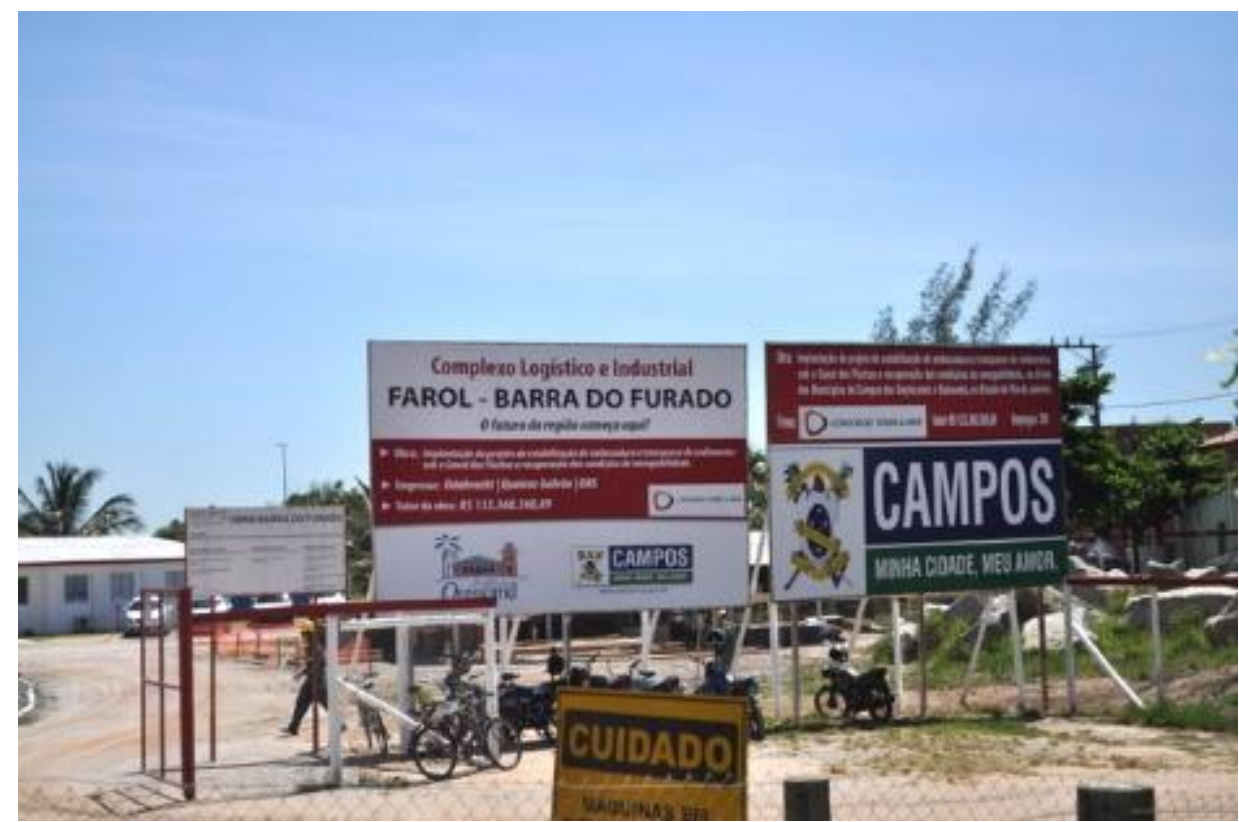

Figura 4. Projeto Farol Barra do Furado - Município de Quissamã. Fonte: www.ururau.com.br, 2012.

Tais transformações apontadas neste tópico influenciaram em uma nova configuração territorial, que pode ser analisada segundo a nova Divisão Regional publicada pelo IBGE (2017).

\section{A nova Divisão Regional em Regiões Geográficas, o exemplo fluminense}

A divisão do espaço geográfico em regiões é uma tarefa de caráter científico ditada tanto por interesses acadêmicos quanto por necessidades do planejamento e da gestão do território. Etimologicamente, o termo região é derivado do latim régio, referindo-se à unidade político-territorial da divisão do Império Romano. Sua raiz é encontrada no verbo regere, governar, tendo o referido termo, originalmente, uma conotação eminentemente política, como apontou Corrêa (1987). Com o decorrer do tempo, esta concepção foi adquirindo nova conotação, passando a designar uma dada porção da superfície terrestre, que através de um critério ou outro, diferencia-se de uma outra porção.

Convém lembrar que o referido termo faz parte do vocabulário do senso comum, como também é um conceito chave da ciência geográfica e no decorrer da história do pensamento geográfico, foi causador de intenso debate entre os geógrafos. É um conceito muito complexo, permitindo diferentes distinções e interpretações. Tais distinções e interpretações não são únicas e nem excludentes, cada uma tendo 
significado próprio, a partir das diferentes correntes do pensamento geográfico (CORRÊA, 1987; BEZZI, 1997).

Não cabe neste artigo tratar das diferentes acepções do conceito de Região, mas Corrêa (1987, p.184) aponta que o referido conceito está associado genericamente à noção de diferenciação de áreas e que "ao longo da história moderna do pensamento geográfico, [tem se constituído] em um de seus conceitos-chave, os outros sendo os de paisagem, espaço, lugar e território". Posto isto, passemos a analisar as duas divisões regionais exemplificadas a partir do território fluminense, estabelecendo comparações entre a divisão de 1991, as denominadas Mesorregiões e Microrregiões Geográficas, e a atual, substituindo os termos anteriores por Regiões Intermediárias e Imediatas (IBGE, 1990; 2017).

Conforme apontado por Magnago (1995, p.85) a partir da publicação do IBGE de 1990

a dinâmica do processo de desenvolvimento capitalista em nosso país, pode ser traduzida pela inevitável desigualdade na organização espacial que comporta diferentes formas de subordinação do trabalho ao capital e pela atuação crescente do papel do Estado naquele processo.

Esse modelo regional, a partir desta concepção teórica, identificou mesorregiões e microrregiões geográficas, que a partir das Unidades da Federação foram universo de análise, tendo por noção a totalidade nacional. $\mathrm{O}$ método utilizado foi a divisão sucessiva destes espaços - as Unidades Federadas (MAGNAGO, 1995). Uma mesorregião geográfica representava "uma área individualizada, em uma unidade da federação, que apresentasse formas do espaço geográfico definidas pelas seguintes dimensões: “...o processo social, como determinante, o quadro natural, como condicionante, a rede de comunicação e de lugares, como elemento de articulação espacial” (IBGE, 1990, apud MAGNAGO, 1995); enquanto as microrregiões geográficas

consideradas como parte das mesorregiões, foram definidas por suas especificidades quanto à estrutura da produção agropecuária, industrial, extrativa mineral e pesqueira. Para compreensão das especificidades da estrutura produtiva, utilizaram-se, também, informações sobre o quadro natural e sobre relações sociais e econômicas particulares, compondo a vida de relações locais (MAGNAGO, 1995, p.86). 
Para o território fluminense, segundo a base teórico-conceitual apontada, foram identificadas seis mesorregiões (mapa 7) e 18 microrregiões geográficas, conforme pode ser observado no mapa 8.

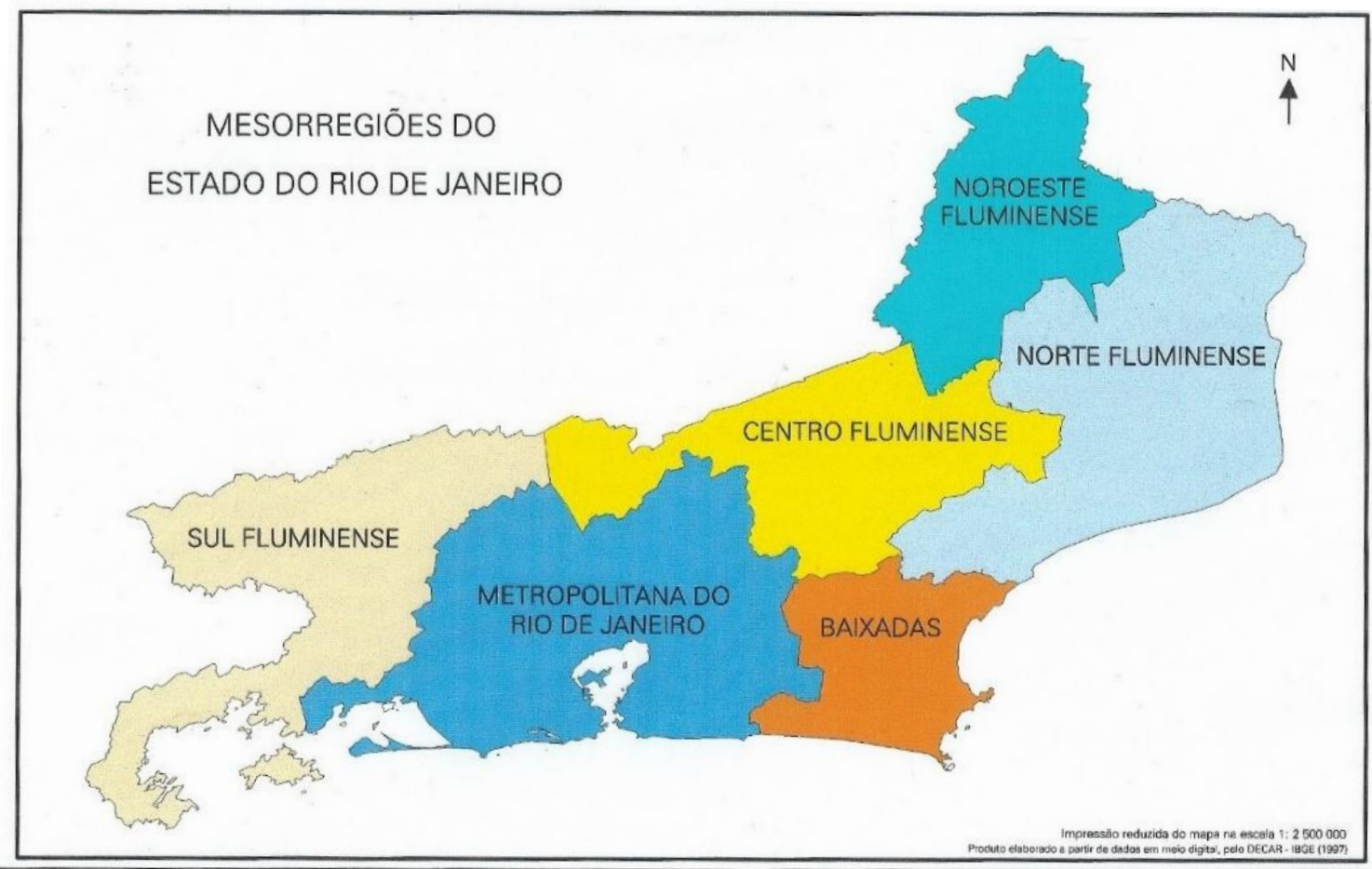

Mapa 7. Fonte: Mapa elaborado por Monica O’Neill a partir de IBGE - Departamento de Geografia, 1990.

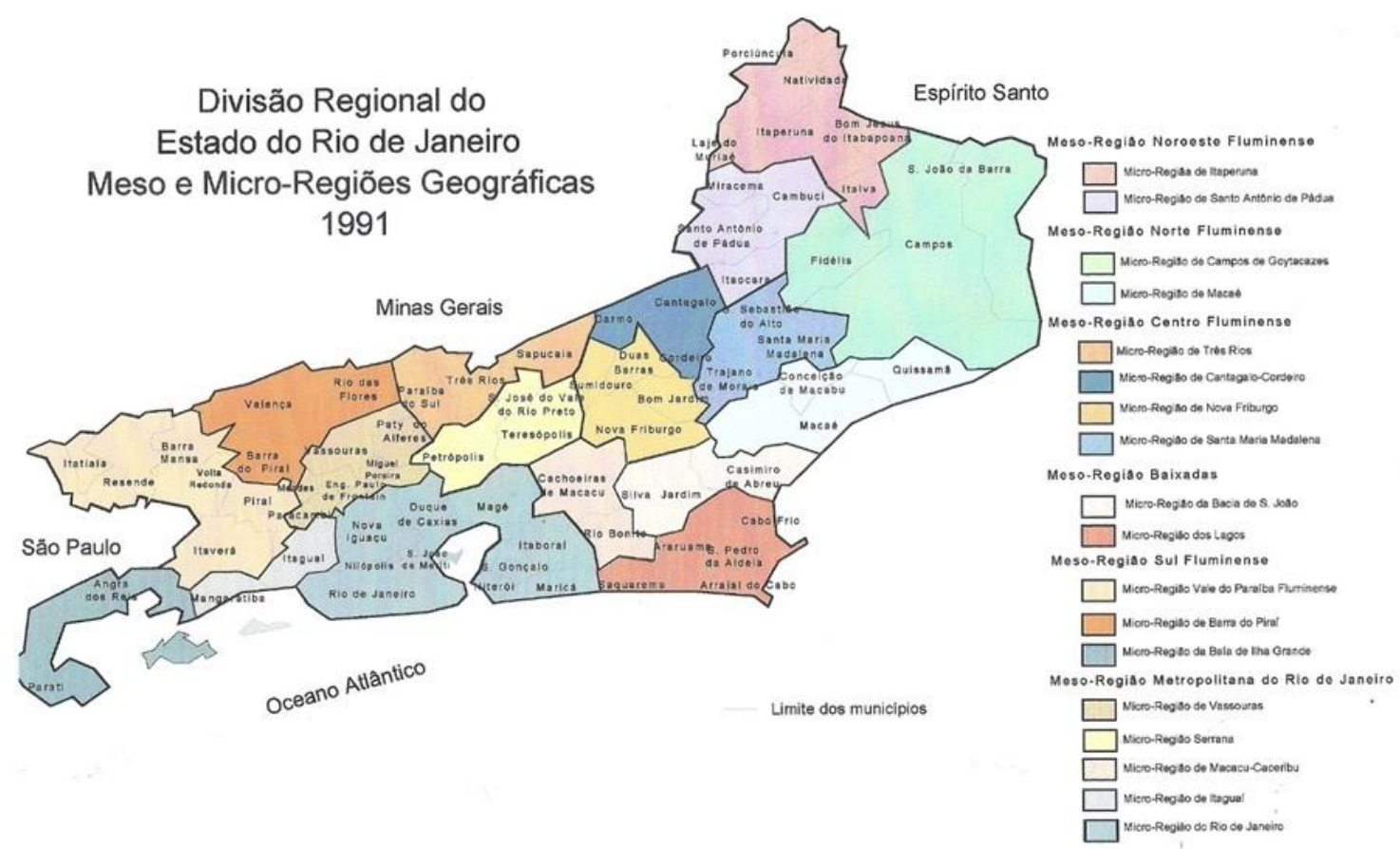


Mapa 8. Fonte: Mapa elaborado por Monica O’Neill a partir de IBGE - Departamento de Geografia, 1990.

Passados mais de 26 anos, a Coordenação de Geografia do IBGE (2017) elaborou uma nova Divisão Regional (mapa 9), na qual foram identificadas cinco Regiões Geográficas Intermediárias (antigas Mesorregiões) e 14 Regiões Geográficas Imediatas (antigas Microrregiões). Cumpre explicitar as diferenças entre a recente delimitação proposta de divisão das Regiões Geográficas e a anterior, a de 1990. Em decorrência da metodologia adotada (anexo 1) para esta nova divisão, a delimitação e proposta, conforme pode ser observado na nomenclatura das respectivas regiões, as cidades tem papel importante, na qual a rede urbana "comanda os fluxos de pessoas e mercadorias, a curta e média distância e dá sentido à vida cotidiana dos residentes" (IBGE, 2017 apud MARQUES, 2017, p.2). Um outro elemento importante dessa nova divisão regional foi estabelecer que cada unidade da federação deveria ter ao menos quatro Regiões Geográficas Imediatas e ao menos duas Regiões Geográficas Intermediárias, respeitando, entretanto, os limites territoriais dos Estados, como na divisão anterior.

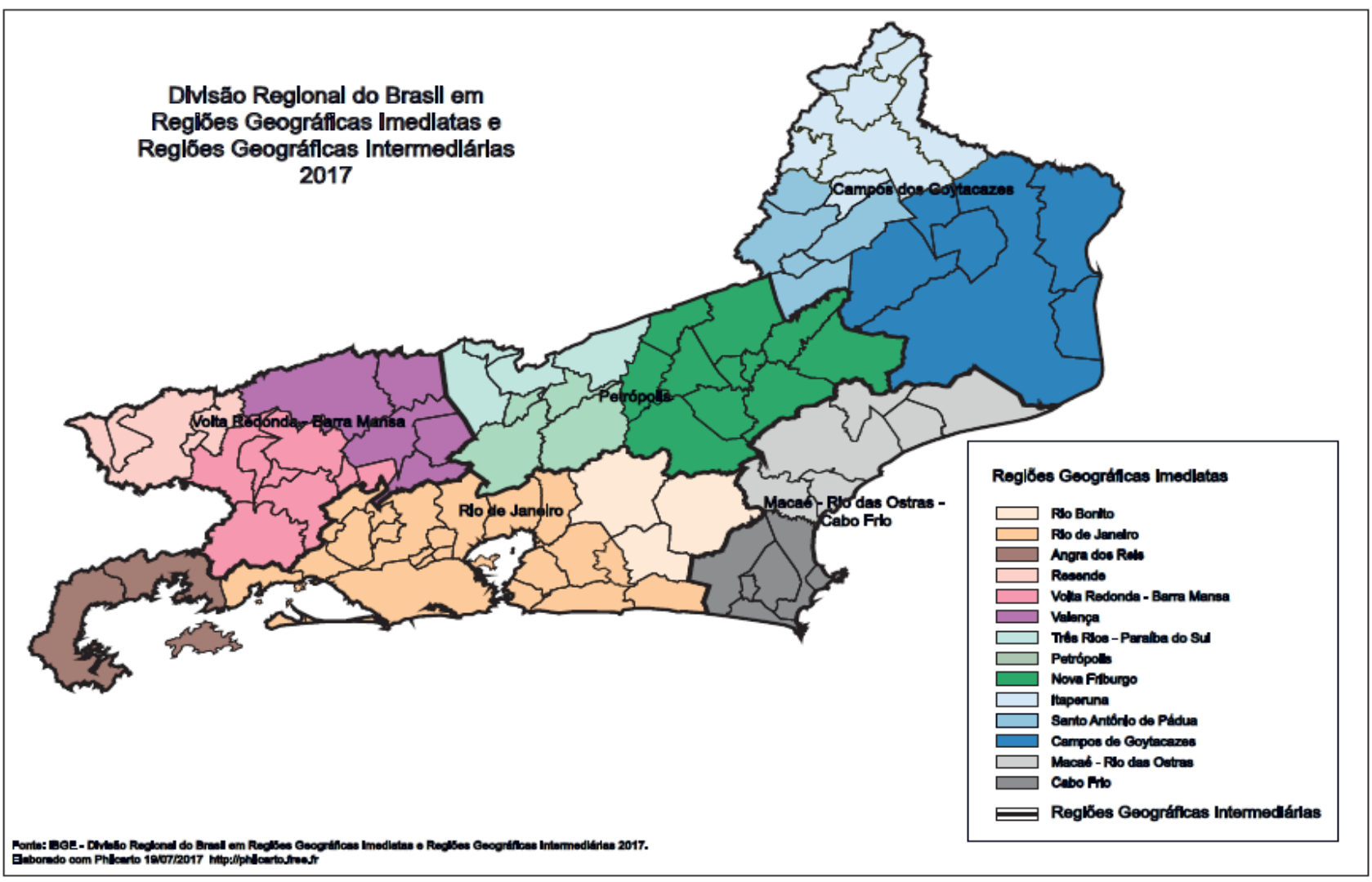

Mapa 9. Fonte: Mapa elaborado por Monica O’Neill a partir de IBGE - Divisão Regional do Brasil em Regiões Geográficas Imediatas e Regiões Geográficas Intermediárias, 2017 
A rede urbana como importante elemento norteador dessa nova delimitação das Regiões Geográficas Intermediárias e Imediatas foi decorrente das transformações já analisadas neste artigo, a partir dos anos 1990, refletindo nas novas relações no território fluminense. Para exemplificar as diferenciações encontradas entre os dois momentos temporais, para este artigo vamos apresentar três exemplos.

1- O primeiro, refere-se à Região Geográfica Intermediária de Macaé-Rio das Ostras-Cabo Frio, apresentando duas Regiões Geográficas Imediatas Macaé-Rio das Ostras e Cabo Frio, ambas com seis municípios no interior de suas áreas de atuação (ver anexo 2). Esta nova Região Geográfica Intermediária, anteriormente era pertencente à Mesorregião Norte Fluminense e constituindo a Microrregião de Macaé, e a Mesorregião Baixadas constituída das Microrregiões dos Lagos e Bacia de São João. Essa nova região geográfica se estrutura a partir das atividades extrativas do petróleo e do recebimento dos royalties pelas referidas prefeituras (NUNES, 2015), além da atividade do lazer vinculado ao turismo e à segunda residência, principalmente nos municípios de Rio das Ostras, Cabo Frio, Araruama e Armação dos Búzios, entre outros (RIBEIRO; COELHO, 2008). Cumpre destacar que configura-se um processo de conurbação entre Macaé-Rio das Ostras, em decorrência dos fluxos diários de população entre os dois municípios (CADENA, 2012); enquanto Cabo Frio é alçada ao patamar de cidade média, em função de suas relações na oferta de bens e serviços à sua área de influência. Esta nova Região Geográfica Imediata, como pode ser observado no mapa de 1991, apresentava, como já explicitado, outra estrutura, devido a essa nova configuração da Divisão territorial do Trabalho interna, como também da própria estrutura territorial que se modificou, com a criação de novos municípios, como Rio das Ostras, anteriormente pertencente, como distrito de Casimiro de Abreu (NUNES, 2015); Armação dos Búzios, antigo distrito de Cabo Frio; e Carapebus, pertencente como distrito de Macaé.

2- 0 segundo, refere-se à Petrópolis, atualmente Região Geográfica Intermediária, passando a constituir uma nova região com 19 municípios, com três Regiões Geográficas Imediatas: Petrópolis com quatro; Nova Friburgo com 11; e Três Rios-Paraíba do Sul, respectivamente com quatro municípios. Tais municípios pertenciam à Microrregião Serrana, incluída na Meso Metropolitana e municípios que integravam as Micros Cantagalo-Cordeiro e Santa Maria 
Madalena, que perdem essa categoria regional, passando para a Região Geográfica Imediata de Nova Friburgo. Três Rios-Paraíba do Sul formam uma Região Geográfica Imediata, antiga Microrregião Três Rios. Como podemos perceber, Nova Friburgo amplia sua área de atuação em nível local, enquanto Petrópolis no nível intermediário, em decorrência de suas transformações socioespaciais, consequentemente ampliando seus alcances espaciais. Tais transformações, em escalas distintas, refletem na Meso Centro-Sul Fluminense, que passa a não existir nessa nova divisão regional, com os municípios que a integravam constituindo as Regiões Geográficas Intermediárias de Volta Redonda-Barra Mansa e Petrópolis. Este novo ordenamento regional resulta de atividades ligadas à moda e vestuário; aos produtos de vestuário e decoração; e à indústria de confecção de moda íntima em Petrópolis, Teresópolis e Nova Friburgo, além de atividades voltadas para o turismo e segunda residência, como também atividades agrícolas, como já mencionado em páginas anteriores com a produção de hortifrutíferos (SEABRA, 2008; 2015ª ; 2015b). As figuras 5, 6, 7 e 8 exemplificam o papel de polo de confecções, vestuário e decoração nos três municípios mencionados.

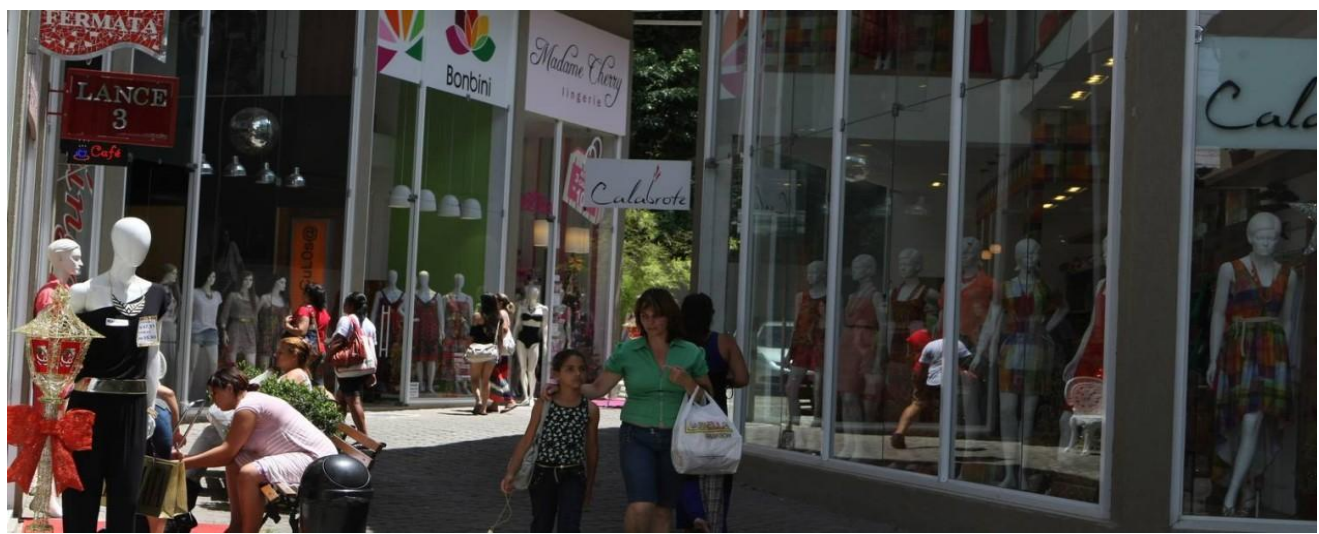

Figura 5. Rua Teresa, no Polo comercial de Petrópolis. Fonte: Jornal O Globo, 2012.

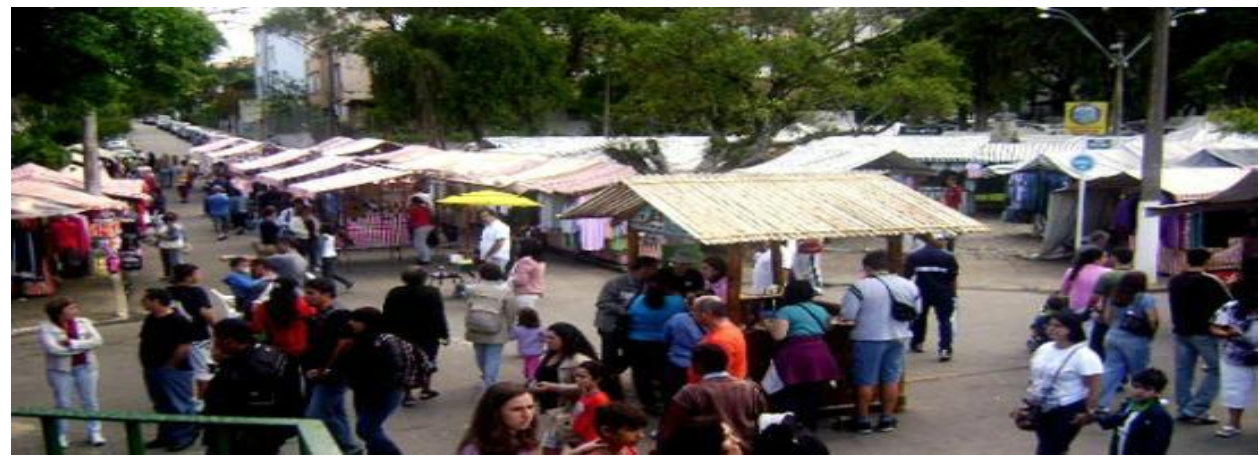

Figura 6. Feira do Alto, em Teresópolis. Fonte: www.tripadvisor.com.br, s/d. 


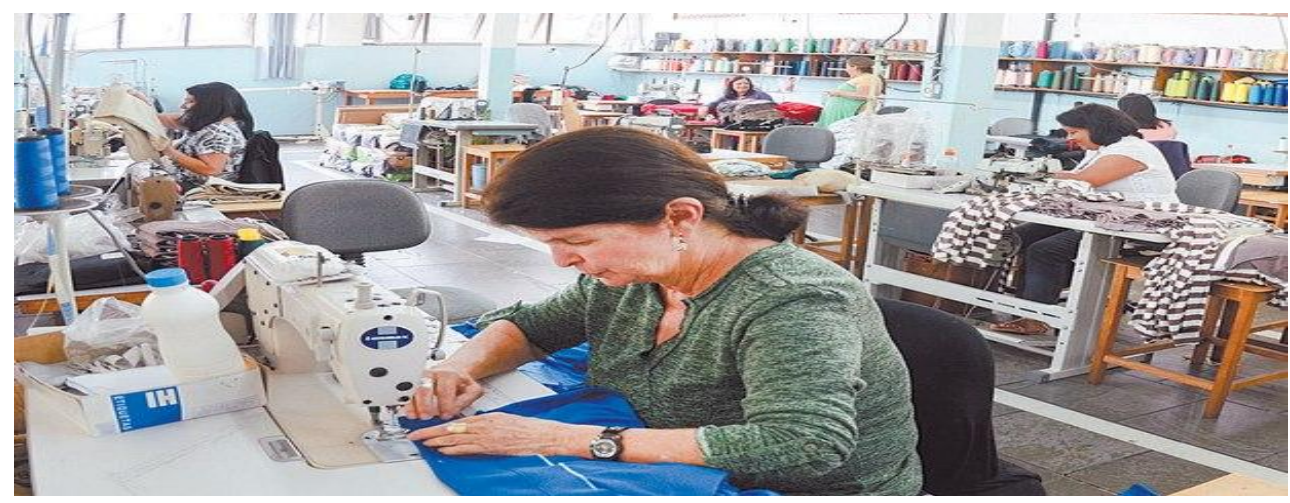

Figura 7. Fonte: Jornal O Dia. Indústria de confecção em Nova Friburgo

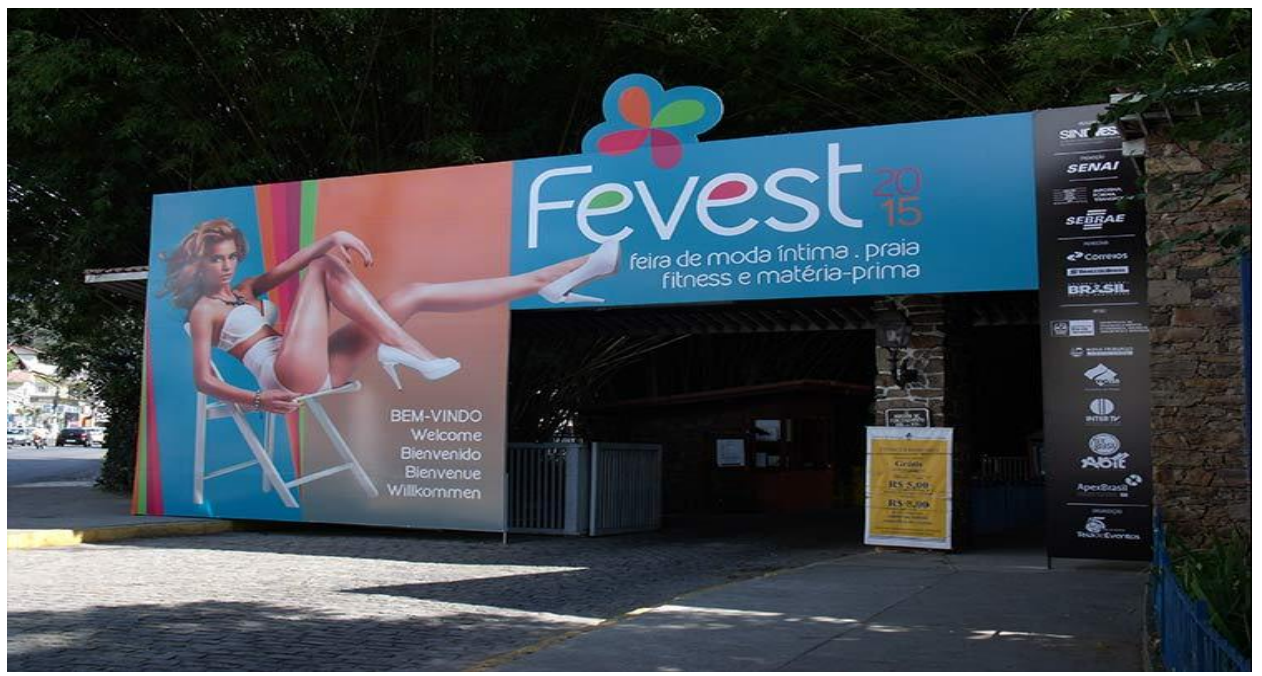

Figura 8. Feira de moda íntima em Nova Friburgo. Fonte: http://www.textilia.net, s/d.

3- Por fim, a Região Geográfica Intermediária do Rio de Janeiro apresenta transformações, pois é acrescida dos municípios de Silva Jardim, pertencente à Microrregião da Bacia de São João e Araruama, incluída na Microrregião dos Lagos, na Mesorregião Baixadas, em 1991. Por outro lado, perde os municípios anteriormente pertencente às Micros Serrana e Vassouras, que integravam a Mesorregião Metropolitana do Rio de Janeiro. A antiga Microrregião de Itaguaí passa à Região Imediata Angra dos Reis e Itaguaí-Mangaratiba passam a integrar a Região Imediata do Rio de Janeiro. Cumpre fazer referência que a Microrregião Vassouras, pertencente em 1991 à Mesorregião Metropolitana do Rio de Janeiro constitui, na Nova Divisão Regional, a Região Imediata de Valença, pertencente à Região Intermediária Volta Redonda-Barra Mansa. Neste sentido, a Região Geográfica Intermediária do Rio de Janeiro é constituída por três Regiões Imediatas: Rio de Janeiro, com 21 municípios; Angra dos Reis, 
com dois municípios, Angra dos Reis e Paraty; além de Rio Bonito, com três municípios (ver anexo 2). Tal configuração é resultante das articulações entre o núcleo metropolitano do Rio de Janeiro, a periferia metropolitana que se expandiu em direção ao norte do estado, com a inclusão de Araruama e Silva Jardim, em decorrência dos projetos, principalmente industriais, implantados neste limite regional e já mencionados neste artigo.

\section{ARRUMANDO AS IDEIAS}

As discussões apresentadas neste artigo remetem e rebatem no recorte territorial fluminense, nas diferenciações entre a Metrópole e o interior, nas transformações econômicas desencadeadas com a nova Divisão Territorial do Trabalho e, consequentemente, na nova configuração regional.

Tais fatores e mudanças podem ser concretamente visualizados no espaço fluminense, uma vez que para a cidade do Rio de Janeiro convergiam os elementos destinados a garantir a realização de suas atividades, tornando seu território um elemento privilegiado na localização de instituições, empresas, infraestrutura e pessoas, deixando marcas que permanecem ainda hoje, como distinguiu Ribeiro e O'Neill (2001).

Consequentemente, o significado e importância nacional da cidade do Rio de Janeiro conduziram ao desenvolvimento de relações assimétricas, com o estado na qual se localiza, gerando um desequilíbrio entre a metrópole e sua hinterlândia, entre o núcleo metropolitano e a periferia, entre o urbano e o rural.

Apesar dessas diferenciações socioespaciais de desequilíbrio, o interior fluminense apresenta municípios que vem destacando-se no contexto econômico e populacional, não podendo negligenciar a importância dos mesmos frente à metrópole, exemplificados neste texto com os novos papeis assumidos nas relações e articulações em níveis locais, microrregionais e estadual de Macaé-Rio das Ostras; Cabo Frio; Petrópolis; Nova Friburgo; Três Rios-Paraíba do Sul, exercendo posição de destaque em suas articulações na rede urbana fluminense, com novas centralidades no comando dos fluxos de pessoas e 
mercadorias em diferentes escalas, nas quais as relações de horizontalidade e verticalidade se fazem mais complexas.

Por outro lado, podemos questionar para onde caminha o estado do Rio de Janeiro neste final de segunda década do século 21, com uma crise institucional de grandes proporções e que rebate no desemprego, na violência, nos salários, nos serviços e nos novos projetos, através do sucateamento da máquina estadual, sem mencionar problemas agravantes de ordem ambiental, tão evidentes nos dias atuais (AGUIAR, no prelo). O mapa 10 representa uma síntese dos impactos ambientais distribuídos pelas oito Regiões de Governo, conforme as atividades econômicas encontradas nestas distintas regiões.

Esta é a grande interrogação que fica para futuro para o território fluminense.

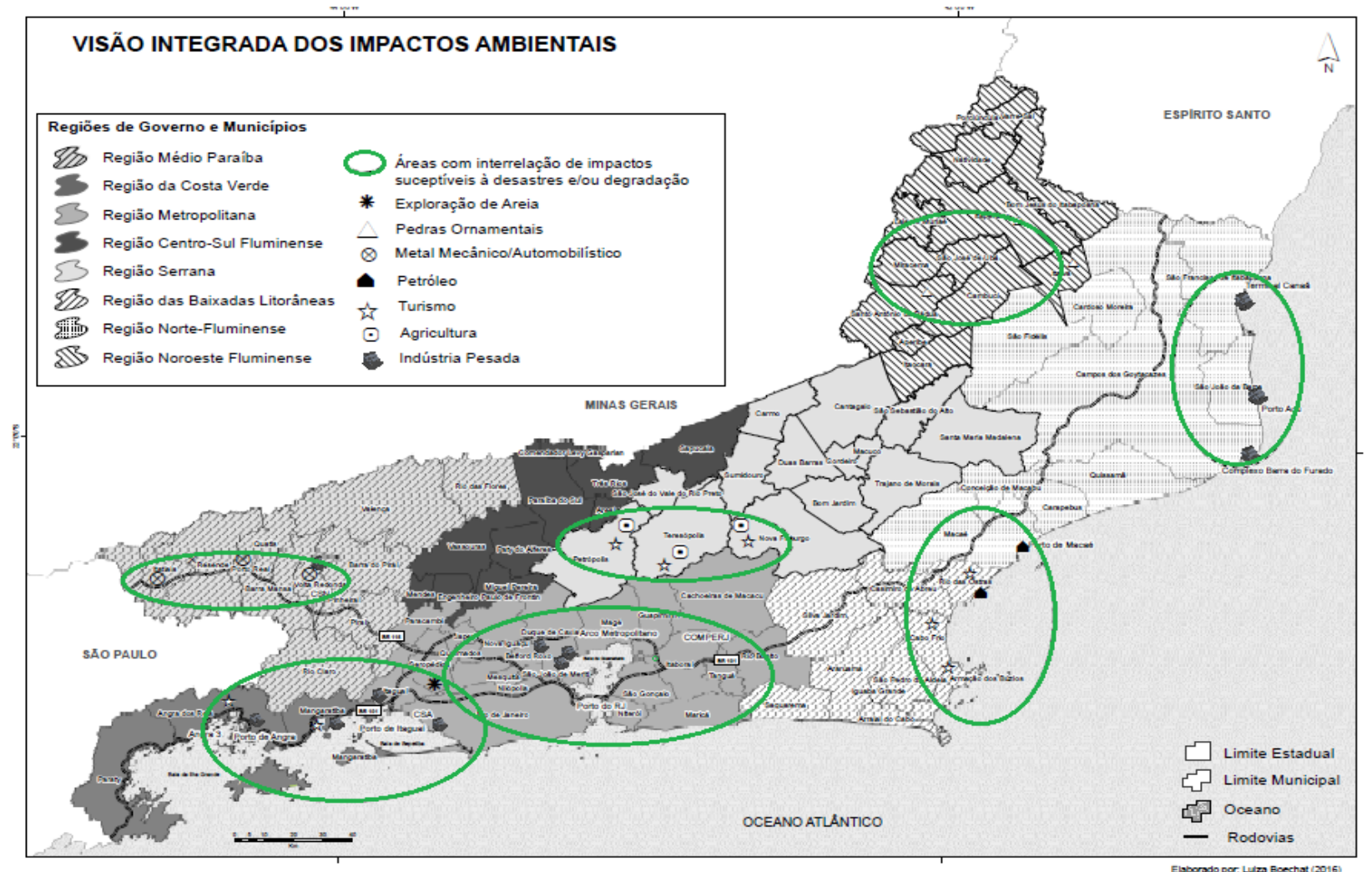

Mapa 10. Fonte: Concepção por Tereza Coni Aguiar. In: Revisitando o Território Fluminense VI (no prelo). 


\section{REFERÊNCIAS}

AGUIAR, Tereza Coni. Uma visão integrada dos impactos ambientais no estado do Rio de Janeiro. In: MARAFON, Glaucio José; RIBEIRO, Miguel Angelo. Revisitando o território Fluminense VI. Rio de Janeiro: EdUERJ (no prelo).

Atlas histórico escolar [por] Manoel Maurício de Albuquerque, Arthur Cézar Ferreira Reis [e] Carlos Delgado de Carvalho. 7. ed. rev. e atual. Rio de Janeiro, FENAME, 1973 160p.

ARAÚJO, Aramis Cortes de. A rede mundial de conectividade das firmas de tecnologia da informação da cidade do Rio de Janeiro. Tese (Doutorado em Geografia) - Programa de Pós-Graduação em Geografia, Universidade do Estado do Rio de Janeiro, 2017.

BAPTISTA, Thiago Jeremias. Os investimentos da República Popular da China no estado do Rio de Janeiro: novas territorialidades no processo de reestruturação territorial fluminense no início do século XXI (2010-2013). Dissertação (Mestrado em Geografia) - Programa de Pós-Graduação em Geografia, Universidade do Estado do Rio de Janeiro, 2016.

BEZZI, Meri Lourdes. Região: uma (re)visão historiográfica - da gênese aos novos paradigmas. 1ª ed. Santa Maria: Editora UFSM, 2004. 259p. 1997. Universidade Federal de Santa Maria.

CADENA, Alberto. Crescimento populacional e os vetores de expansão urbana em Macaé-RJ. In: MARAFON, Glaucio José; RIBEIRO, Miguel Angelo. Revisitando o território Fluminense IV. Rio de Janeiro: Gramma, 2012. P.229-244. P.312p.

CORRÊA, Roberto Lobato. Região e organização espacial. Rio de Janeiro: Editora Ática, 2000.

DAVIDOVICH, Fani Raquel. Estado do Rio de Janeiro: singularidades de um contexto territorial. Território, Rio de Janeiro: LAGET/UFRJ, nº9, p.9-24, jul-dez.2000.

DIAS, Alexandre Pessoa et al. Complexo Petroquímico do Rio de Janeiro (Comperj): Impactos socioambientais, violação de direitos e conflitos na Baía de Guanabara. Revista Ética e Filosofia Política - № 16 -Volume 1 - junho de 2013.

DICIONÁRIO HOUAISS DA LÍNGUA PORTUGUESA. Instituto Antônio Houaiss. Rio de Janeiro: Objetiva, p.1361, 2009.

Divisão do Brasil em Mesorregiões e Microrregiões Geográficas. Rio de Janeiro: IBGE, 1990.

Divisão regional do Brasil em Regiões Geográficas Imediatas e Regiões Geográficas Intermediárias: 2017/IBGE, Coordenação de Geografia - Rio de Janeiro: IBGE, 2017.

EVANGELISTA, Helio de Araújo. A fusão dos estados da Guanabara e Rio de Janeiro segundo uma perspectiva geográfica. 1998.

GALVÃO, Maria do Carmo Corrêa. O espaço agrário fluminense - estrutura e transformações. In: Revista Geográfica, Instituto Panamericano de Geografia e História, México, nº 105. P.119-131. 1987.

IPEA. Anais do I Circuito de Debates Acadêmicos. Rio de Janeiro, 2011. 21p. Disponível em http://www.ipea.gov.br/code2011/chamada2011/pdf/area7/area7-artigo18.pdf acesso realizado em 15 de Setembro de 2017.

LESSA, Carlos. O Rio de todos os brasis [Uma reflexão em busca de autoestima]. Rio de Janeiro/São Paulo: Editora Record, 2000. 478p.

MAGNAGO, Angélica Alves. A divisão regional brasileira - uma revisão bibliográfica. In: Revista Brasileira de Geografia. Rio de Janeiro: IBGE, v.55, n.4. p.65-92, Out./dez.1995.

MARAFON, Glaucio José; RUA, João; RIBEIRO, Miguel Angelo et al. Atividade turística no Estado do Rio de Janeiro. In: Revista de Economia Fluminense - Estratégias para o Desenvolvimento. Ano 5, no 09. Dez 2010. Rio de Janeiro: Fundação CEPERJ, 2004. P.32-35. 
MARAFON, Glaucio José; RIBEIRO, Miguel Angelo. Agricultura familiar, pluriatividade e turismo rural: reflexões a partir do território fluminense. In: Revista Brasileira de Geografia. Rio de Janeiro, v.59, n.2, p.83-97, jul./dez.2005.

MARAFON, Glaucio José; RIBEIRO, Miguel Angelo et al. (orgs.). Regiões de governo do estado do Rio de Janeiro: uma contribuição geográfica. Rio de Janeiro: Gramma, 2005.

MARAFON, Glaucio José. Relações campo-cidade: uma leitura a partir do território fluminense. In: MARAFON, Glaucio José; RIBEIRO, Miguel Angelo. Revisitando o território Fluminense IV. Rio de Janeiro: Gramma, 2012. P.129-139. 312p.

MORAIS, Alex Pereira de. Considerações sobre o papel dos royalties e participações espaciais de petróleo e gás sobre a economia dos municípios confrontantes com a Bacia de Campos. In: MARAFON, Glaucio José; RIBEIRO, Miguel Angelo (orgs.). Revisitando o Território Fluminense III. Rio de Janeiro: Gramma, 2010. P.243-273. 332p.

MOREIRA, Rui (org.). A reestruturação Industrial e Espacial do Estado do Rio de Janeiro. Geografia GERET/NEGT/GECEL. Niterói, 2003. 170p.

MOTA, Carlos Guilherme; LOPEZ, Adriana. História do Brasil: uma interpretação. São Paulo: Editora 34, 2016. $5^{\mathrm{a}}$ ed. $1136 \mathrm{p}$.

NUNES, Nathan da Silva. Transformações nas dinâmicas populacional e econômica a partir dos impactos dos royalties petrolíferos no município de Casimiro de Abreu-RJ. 56f. Monografia (Graduação em Geografia) - Instituto de Geografia, Universidade do Estado do Rio de Janeiro, 2015.

OLIVEIRA, Floriano J. Godinho de. Reestruturação produtiva, território e poder no Rio de Janeiro. Garamond, Rio de Janeiro, 2008.

OLIVEIRA, Rafael da Silva. As transformações na organização espacial do município de Nova Iguaçu: uma leitura a partir dos eixos de transportes. Universidade Federal Fluminense, 2005.

PACHECO, Susana Mara Miranda. Terceirização e reestruturação urbana no Rio de Janeiro, Boletim GETER, 1 (1), 1998.

PACHECO, Wedson Felipe Cabral. Porto do Açu, o "X" da questão: a implantação no município de São João da Barra-RJ. In: MARAFON, Glaucio José; RIBEIRO, Miguel Angelo. Revisitando o Território Fluminense V. Rio de Janeiro: Gramma, 2015. P.345-357. 376p.

RIBEIRO, Miguel Angelo; O’NEILL, Maria Monica Vieira Caetano. Atlas do Estado do Rio de Janeiro. Rio de Janeiro, 2000. CD-ROM.

RIBEIRO, Miguel Angelo. Considerações sobre o espaço fluminense: estrutura e transformações. In: MARAFON, Glaucio José; RIBEIRO, Marta Foeppel (orgs.). Estudos de Geografia Fluminense. Rio de Janeiro: UERJ/CTC-IGEO-Departamento de Geografia, 2002. P.13-26. 208p.

RIBEIRO, Miguel Angelo. O papel dos centros urbanos na rede de localidades centrais fluminense: Campos dos Goytacazes, Macaé, Itaperuna - 1966/2007. In: Revista de Economia Fluminense - Estratégias para o Desenvolvimento. Ano 5, nº 09. Dez 2010. Rio de Janeiro: Fundação CEPERJ, 2004. P.20-23.

RIBEIRO, Miguel Angelo; COELHO, Maria do Socorro Alves. A importância do fenômeno da segunda habitação e suas implicações com a atividade de lazer-veraneio: o exemplo do estado do Rio de Janeiro. In: MARAFON, Glaucio José; PESSÔA, Vera Lúcia Salazar (orgs.). Agricultura, desenvolvimento e transformações socioespaciais - reflexões interinstitucionais e constituição de grupos de pesquisa no rural e no urbano. Uberlândia: Editora Assis Ltda, 2008. P.303318.

RIBEIRO, Miguel Angelo; CAVALCANTI, Vera Maria d'Ávila. Tipologia urbana no estado do Rio de Janeiro ao final do milênio. As cidades e a urbanização no Brasil: passado, presente, futuro. Florianópolis: INSULAR, 2011. P.147-158.

RIBEIRO, Miguel Angelo; O'NEILL, Maria Monica Vieira Caetano. Considerações sobre a dinâmica populacional fluminense: contrastes entre a metrópole e o interior. In: MARAFON, Glaucio José; RIBEIRO, Miguel Angelo. Revisitando o Território Fluminense IV. Rio de Janeiro: Gramma, 2012. P.199-228. 312p. 
RIBEIRO, Miguel Angelo; O’NEILL, Maria Monica Vieira Caetano. Contrastes entre a metrópole e o interior fluminense a partir do urbano e do rural. In: Velhos saberes, novas abordagens: a Geografia à luz da contemporaneidade / Organização: Ulisses da Silva Fernandes, Miguel Angelo Campos Ribeiro, Nilton Abranches Junior. 1ª ed. Rio de Janeiro - Gramma, 2015. P.1-15. 239p.

RIBEIRO, Miguel Angelo Campos. O papel de Nova Friburgo na rede de localidades centrais fluminense: uma análise comparativa 1966-2007. Geo UERJ (2007), v. 29, p. 452-472, 2016.

SANTOS, Milton; SILVEIRA, Maria Laura. Brasil: Território e sociedade no início do século XXI. Rio de Janeiro: Record, 2001, 471p.

SEABRA, Rogério dos Santos. Redes de distribuição de produtos agrícolas: o papel dos supermercados. In: MARAFON, Glaucio José; RIBEIRO, Miguel Angelo (orgs.). Revisitando o Território Fluminense II. Rio de Janeiro: Gramma, 2008. P.63-81.

SEABRA, Rogério. Função pública e comercialização agrícola: o sistema SEASA-RJ e a entrada das grandes redes de supermercado. In: MARAFON, Glaucio José; RIBEIRO, Miguel Angelo. Revisitando o Território Fluminense V. Rio de Janeiro: Gramma, 2015a. P.299-307. 376p.

SEABRA, Rogério. A rede de comercialização agrícola no Estado do Rio de Janeiro: articulações, processos e fluxos nas novas formas de abastecimento alimentar. Tese (Doutorado em Geografia) - Programa de Pós-Graduação em Geografia, Universidade do Estado do Rio de Janeiro, 2015b. 


\section{ANEXO 1}

\section{IBGE: DELIMITAÇÃO DAS REGIÕES GEOGRÁFICAS INTERMEDIÁRIAS E IMEDIATAS - A METODOLOGIA DE PESQUISA}

\section{Por Paulo Wagner Marques}

Esse projeto nasceu da necessidade de atualizar o quadro territorial brasileiro nas escalas Micro e Mesorregionais. Desde o momento do lançamento das Microrregiões e Mesorregiões Geográficas, em 1989, o território brasileiro passou por profundas alterações, especialmente nos estados onde a rede urbana era menos consolidada, como os da Região Norte e os da Região Centro-Oeste. Por outro lado, mesmo para os estados do sul e do sudeste, como o Rio Grande do Sul e Minas Gerais, onde a rede urbana apresentava-se mais robusta, havia a necessidade de uma atualização desses recortes devido ao expressivo aumento no quantitativo de municípios depois da Constituição de 1988.

Por falar na Constituição de 1988, ela prevê, em seu artigo 25, que os estados são os responsáveis pelo recorte de microrregiões para fins de seu planejamento, organização e execução de funções públicas. A Constituição, assim, é omissa em relação às mesorregiões e limita a criação de microrregiões às tarefas elencadas. Ao mesmo tempo, ela não cria qualquer restrição a quantos conjuntos de microrregiões possam vir a ser criados e não estabelece critérios mínimos de balizamento para a sua elaboração. Ou seja, é possível que existam inúmeros conjuntos de microrregiões por estado. Por exemplo, um para Segurança Pública, outro para Educação, outro para Saúde e assim sucessivamente, o que inviabiliza qualquer planejamento integrado nos próprios estados e torna a divulgação de estatísticas para esses estados, nas escalas propostas, especialmente complicada. E a falta de critérios balizadores tornou inviável que se fizesse uma colagem das microrregiões estaduais em uma escala Brasil, já que cada estado escolhe os critérios para confecção das microrregiões da forma que melhor lhes interessam.

Assim, devido à heterogeneidade das microrregiões estaduais, à omissão da Constituição em relação às mesorregiões e à necessidade de atualização dos recortes dessas escalas em função da dinamicidade do território brasileiro, o IBGE resolveu empreender as pesquisas necessárias para elaborar os recortes 
territoriais nas escalas micro e mesorregionais, tendo em vista a missão do órgão de produzir estatísticas que sejam representativas para a sociedade brasileira.

Esse trabalho começou em 2013 e contou com a participação dos estados e da academia. Pela primeira vez em uma pesquisa da Coordenação de Geografia, as Unidades Estaduais e as Agências do IBGE foram consultadas e chamadas a participar ativamente na elaboração dos trabalhos. Foram feitos trabalhos de campo em 14 estados e mais de $11.000 \mathrm{~km}$ foram percorridos pelos técnicos da Coordenação de Geografia (4 técnicos fixos no projeto, contando comigo, e a eventual ajuda de algum outro técnico da minha gerência). Houve transparência total em relação ao trabalho realizado e todos os estados brasileiros foram convidados a opinar e dar sua contribuição, seja por meio de suas secretarias de planejamento, institutos de estatística e geografia ou outra secretaria responsável pelas divisões estaduais. Na Paraíba, contamos com o auxílio do José Jakson Amâncio Alves, que se não me engano é da UFPB.

A equipe aproveitou todo o cipoal de informações levantadas pelo IBGE em suas pesquisas para a elaboração dos recortes. Assim, informações do Censo 2010, como as que tratam de deslocamentos para trabalho e estudo, do REGIC, das Divisões Urbano Regionais e outras pesquisas já existentes foram usadas para embasar o trabalho. Esses dados permitiram, por meio de intenso uso de Sistemas de Informação Geográfica, desvendar novas centralidades. Na verdade, essas novas centralidades já vinham sendo captadas pelas pesquisas do IBGE, e consideradas no espaço vivido das populações locais, mas a análise dos dados nunca havia sido realizada com o objetivo específico de desvendá-las.

Em relação aos critérios, a rede urbana brasileira foi escolhida por nós para embasar o projeto. Mais do que qualquer outro aspecto atualmente, é a rede urbana que comanda os fluxos de pessoas e mercadorias, a curta e média distância, e dá sentido à vida cotidiana da população. Pensando na coleta e divulgação de estatísticas por parte do IBGE, bem como em base para o planejamento estatal, a rede urbana é o critério que apresenta as respostas mais aderentes à realidade da população brasileira. Por esse motivo, também, optamos por não usar nomes consagrados em divisões anteriores, como "Triângulo Mineiro", "Baixo São Francisco", entre outros, na nomenclatura das novas micros e mesorregiões elaboradas. Geralmente, elas seguem o nome da principal cidade do recorte. 
A metodologia é um capítulo a parte. Precisamos adaptar os critérios usados às diferentes realidade urbanas do país. Não fazia sentido usar os mesmo quantitativos para traçar os recortes territoriais em São Paulo e em Roraima. Então, optou-se por tratar os diferentes de forma diferente, mas dentro das mesmas balizas. Por exemplo, a Região Norte e a Região Centro-Oeste tiveram os números de população mínimos reduzidos para a criação de Regiões Geográficas Imediatas (RGI), sempre que houvesse a necessidade de se criar uma RGI com menos de 5 municípios (número mínimo da metodologia, comportando exceções, como no caso da Microrregião de Angra dos Reis). Outro exemplo foi o sistema de transportes, que também foi usado no trabalho, e que teve o seu padrão alterado no caso do Amazonas e em alguns momentos no Pará. Lá, os rios foram usados como elemento de coesão das RGIs (sugestão da SUDAM). Entretanto, em qualquer estado brasileiro, as seguintes regras de ouro foram seguidas:

- As Regiões Geográficas Imediatas e Intermediárias deveriam respeitar os limites territoriais dos estados;

- Todo estado deveria ter ao menos 4 Regiões Geográficas Imediatas;

- Todo estado deveria ter ao menos 2 Regiões Geográficas Intermediárias.

A primeira regra de ouro acabou por separar algumas Concentrações Urbanas, como Petrolina e Juazeiro. A segunda e a terceira foram necessárias no caso dos estados do Amapá e de Roraima, e em menor grau no Acre.

O Rio de Janeiro apresentou 2 casos de exceção nas RGIs: Angra dos Reis e Rio Bonito. 0 primeiro caso foi devido ao relativo isolamento geográfico, que faz com que Angra dos Reis e Paraty formem uma unidade coesa, com quantidade populacional significativa; já Rio Bonito não compõe nenhum Arranjo Populacional, apesar de estar próximo de vários, e apresenta uma pequena centralidade, suficiente para isolá-lo em uma RGI devido aos contingentes populacionais somados aos dos outros 2 municípios que fazem parte de sua RGI - Cachoeira de Macacu e Silva Jardim.

Fonte: Resumo elaborado a partir de IBGE, 2017. 
ANEXO 2

ESTADO DO RIO DE JANEIRO: DELIMITAÇÃO DAS REGIÕES GEOGRÁFICAS INTERMEDIÁRIAS

E IMEDIATAS, 2017.

\begin{tabular}{|c|c|c|c|c|c|c|}
\hline UF.C.2 & Estado & Códgo RGint & Regiăo Geográrica Intermediấna & Código RGI & Regiäo Geográfica Imediata (RGI) & Geocódigo \\
\hline \multirow[t]{22}{*}{33} & \multicolumn{2}{|c|}{ Rio de vaneiro } & & & & \\
\hline & \multicolumn{2}{|c|}{3301} & Rio de Janeiro & & & \\
\hline & & & & 330012 & Pio de Janeiro & \\
\hline & & & & & & 3304557 \\
\hline & & & & & & 3304904 \\
\hline & & & & & & 3301702 \\
\hline & & & & & & 3303500 \\
\hline & & & & & & 3303302 \\
\hline & & & & & & 3300456 \\
\hline & & & & & & 3305109 \\
\hline & & & & & & ${ }^{\prime} 3302502$ \\
\hline & & & & & & 3301900 \\
\hline & & & & & & 3302858 \\
\hline & & & & & & 3303203 \\
\hline & & & & & & 3302700 \\
\hline & & & & & & 3304144 \\
\hline & & & & & & 3302007 \\
\hline & & & & & & 3302270 \\
\hline & & & & & & 3305505 \\
\hline & & & & & & 3305554 \\
\hline & & & & & & 3301850 \\
\hline & & & & & & ' 3303609 \\
\hline & & & & & & 3302601 \\
\hline
\end{tabular}

Municipios

Populaçăo 2016

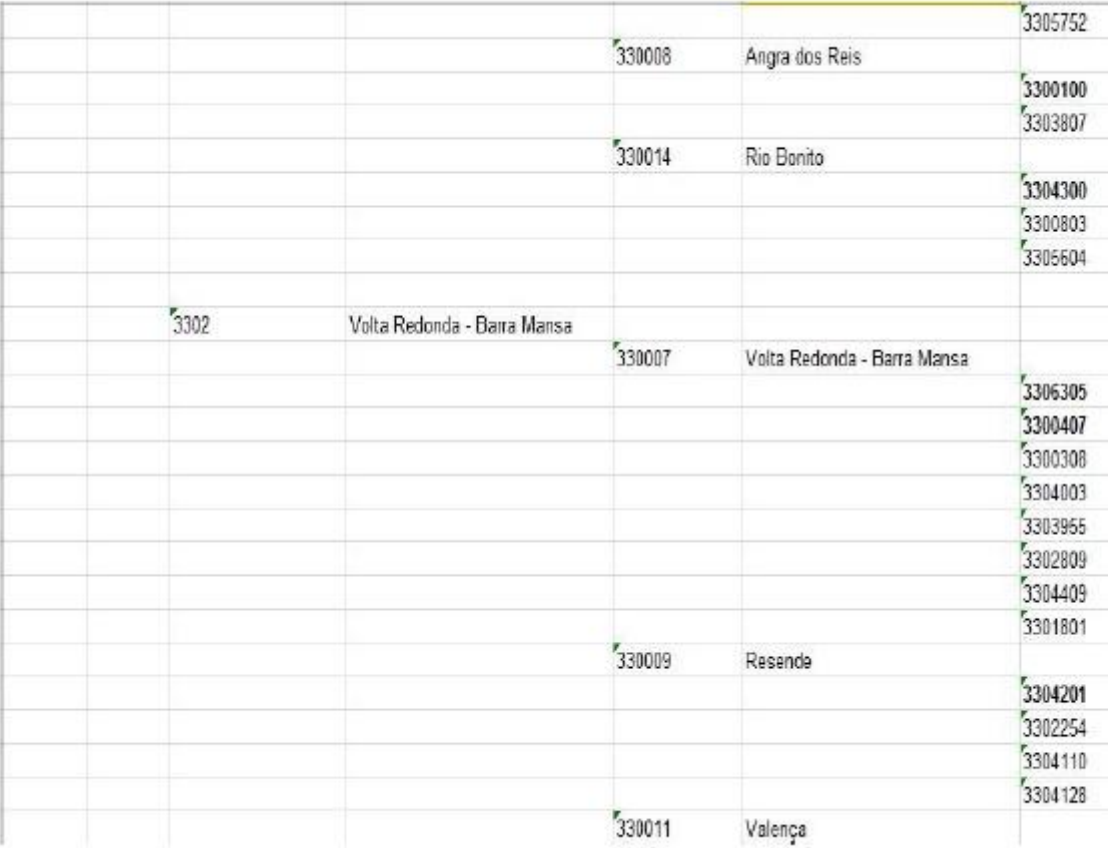

\begin{tabular}{|l|r|}
\hline Tanguá & 32.703 \\
\hline Angra dos Reis & 232.479 \\
\hline Paraty & 191.504 \\
\hline & 40.975 \\
\hline Rio Bonito & 135.845 \\
\hline Cachogiras de Mlacacu & 57.963 \\
\hline Silva Jardim & 56.603 \\
& 21.279 \\
\hline & 1001.716 \\
\hline Volta Redonda & 642.583 \\
\hline Barra llansa & 263.659 \\
\hline Barra do Prai & 180.126 \\
\hline Pirai & 97.152 \\
\hline Pinheiral & 28.088 \\
\hline Mendes & 24.075 \\
\hline Rio Claro & 18.111 \\
\hline Engenhheiro Paulo de Frontin & 17.650 \\
\hline & 13.521 \\
\hline Resende & 188.777 \\
\hline Itatiaia & 126.084 \\
\hline Poito Real & 30.475 \\
\hline Qualis & 18.552 \\
\hline & 13.666 \\
\hline
\end{tabular}




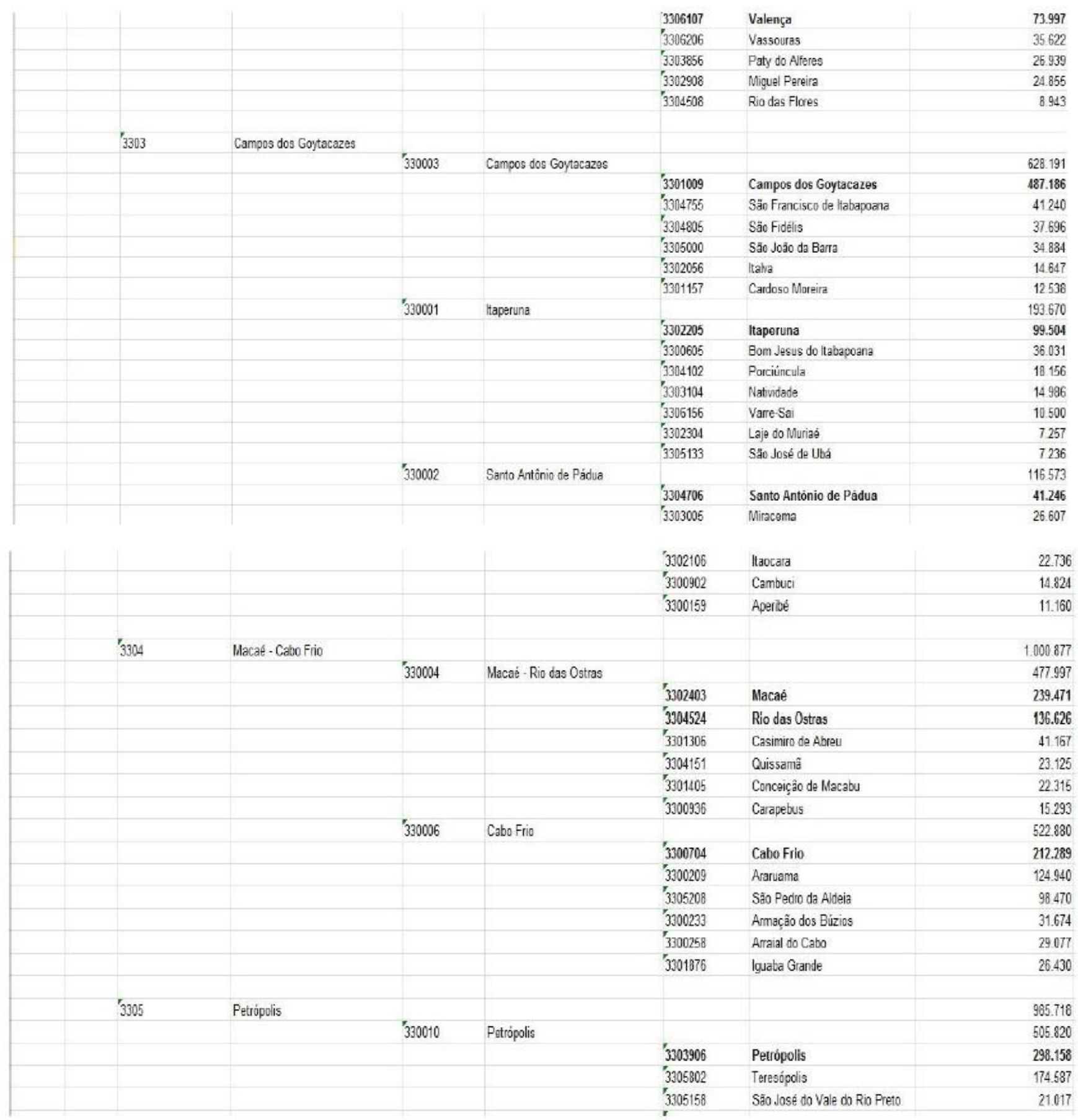




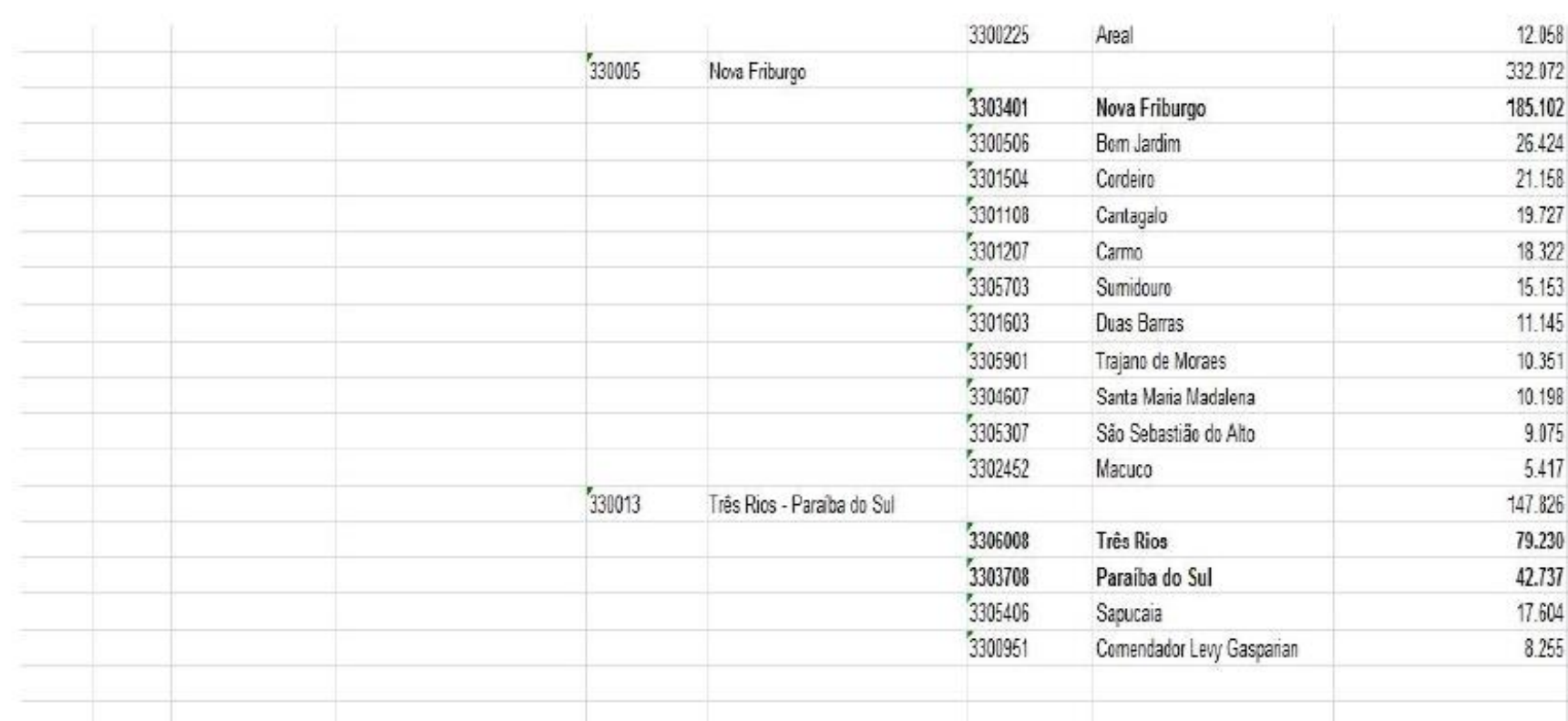

Fonte: Elaborado por NUNES, Nathan. A partir de IBGE - Divisão do Brasil em Regiões Geográficas Imediatas e Regiões Geográficas Intermediárias, 2017. 